\title{
Analgesic effects of Pha1 $\beta$ toxin: a review of mechanisms of action involving pain pathways
}

\author{
Juliana Figueira da Silva ${ }^{1}$ ㅇ, Nancy Scardua Binda ${ }^{1}$, Elizete Maria Rita Pereira ${ }^{2}$, Mário Sérgio Lima de Lavor $^{3}$ @ \\ Luciene Bruno Vieira ${ }^{4}(0)$, Alessandra Hubner de Souza ${ }^{2}$, Flávia Karine Rigo ${ }^{5}$, Hèlia Tenza Ferrer ${ }^{6}(\mathbb{0}$, \\ Célio José de Castro Júnior ${ }^{2}$ (D), Juliano Ferreira ${ }^{7}$, Marcus Vinicius Gomez ${ }^{2,6 *}$ (1) \\ ${ }^{1}$ Laboratory of Pharmacology, Department of Pharmacy, Federal University of Ouro Preto, Ouro Preto, MG, Brazil. \\ ${ }^{2}$ Graduate Program in Health Sciences, Institute of Education and Research, Santa Casa de Belo Horizonte, Belo Horizonte, MG, Brazil. \\ ${ }^{3}$ Graduate Program in Animal Sciences, State University of Santa Cruz (UESC), Ilhéus, BA, Brazil. \\ ${ }^{4}$ Department of Pharmacology, Institute of Biological Sciences (ICB), Federal University of Minas Gerais (UFMG), Belo Horizonte, MG, Brazil. \\ ${ }^{5}$ Graduate Program in Health Sciences, University of the Extreme South of Santa Catarina (UNESC), Criciuma, SC, Brazil. \\ ${ }^{6}$ Center of Technology in Molecular Medicine, School of Medicine, Federal University of Minas Gerais (UFMG), Belo Horizonte, MG, Brazil. \\ ${ }^{7}$ Department of Pharmacology, Federal University of Santa Catarina, Florianópolis, SC, Brazil.
}

\section{Keywords: \\ Pain}

Analgesia

Pha1 $\beta$ peptide

CTK 01512-2

Voltage-activated calcium channels TRPA1

\begin{abstract}
Pha1 $\beta$ is a neurotoxin purified from spider venom that acts as a high-voltage-activated (HVA) calcium channel blocker. This spider peptide has shown a high selectivity for $\mathrm{N}$-type HVA calcium channels (NVACC) and an analgesic effect in several animal models of pain. Its activity was associated with a reduction in calcium transients, glutamate release, and reactive oxygen species production from the spinal cord tissue and dorsal ganglia root (DRG) in rats and mice. It has been reported that intrathecal (i.t.) administration of $\mathrm{Ph} \alpha 1 \beta$ to treat chronic pain reverted opioid tolerance with a safer profile than $\omega$-conotoxin MVIIA, a highly selective NVACC blocker. Following a recent development of recombinant Pha1 $\beta$ (CTK 01512-2), a new molecular target, TRPA1, the structural arrangement of disulphide bridges, and an effect on glial plasticity have been identified. CTK 01512-2 reproduced the antinociceptive effects of the native toxin not only after the intrathecal but also after the intravenous administration. Herein, we review the Pha1 $\beta$ antinociceptive activity in the most relevant pain models and its mechanisms of action, highlighting the impact of CTK 01512-2 synthesis and its potential for multimodal analgesia.
\end{abstract}

* Correspondence: marcusvgomez@gmail.com https://doi.org/10.1590/1678-9199-JVATITD-2021-0001

Received: 03 January 2021; Accepted: 26 March 2021; Published online: 22 November 2021 


\section{Background}

Pain is an unpleasant sensory and emotional experience associated with actual or potential tissue damage as described by the International Association for the Study of Pain (IASP). It can serve as an index of the severity and activity of a disease condition, a prognostic indicator, and a criterion of treatment efficacy [1]. Chronic pain has an undeniable impact on a patient's quality of life, with possible financial consequences. Institutional costs associated with chronic pain at a major city university health network hospital in Canada have been estimated to range between CAN\$2.5 million and CAN\$4.1 million yearly [2].

Neuropathic pain (NP), an example of chronic pathological pain, is complex to manage [3]. NP can be moderated with a wide range of medicines such as tricyclic antidepressants, serotoninnoradrenaline reuptake inhibitors, and calcium-channel-acting modulators (pregabalin and gabapentin) [4]. Ziconotide (Prialt ${ }^{\circledR}$; Elan Pharmaceuticals, San Diego, CA, USA), a synthetic version of $\omega$-conotoxin MVIIA, the $\mathrm{Ca}_{\mathrm{v}} 2.2$ channel blocker, was introduced for the treatment of severe chronic pain that was not relieved by systemic analgesics, adjunctive therapies, or intrathecal morphine [5-8]. Although effective, ziconotide has limited use because of the requirement for i.t. administration coupled with serious neurological and psychiatric adverse events [9].

Studies on Phoneutria nigriventer venom showed that Pha1 $\beta$ toxin could inhibit high-voltage-activated (HVA) calcium channel currents and was more potent and effective in inhibiting Ca 2.2 channels - N-type voltage-activated calcium channels (NVACC) currents [10]. Pha1 $\beta$ has been shown in many relevant pain models to affect three different types of pain: nociceptive, inflammatory, and pathological [11]. The spider peptide was effective and safe in all tested rodent nociception models [11]. Pha1 $\beta$ demonstrated an extensive analgesic effect with fewer side effects than $\omega$-conotoxin MVIIA, explained by its blockade of HVA calcium channels. Further studies found that Pha1 $\beta$ is an antagonist of the TRPA1 receptor that is also involved in the nociceptive process [12]. The antinociceptive and adverse effects produced by the native toxin form were fully mimicked by its recombinant version, CTK 01512-2, in several pain models [13]. This review focuses on the mechanisms related to the analgesic effect and safety profile of native Pha1 $\beta$ and its recombinant form.

\section{Pha1 $\beta$ toxin effects in most relevant animal pain models}

Experiments on pain using human subjects are ethically limiting, subjective, and practically challenging. Hence, animal models of pain are extensively used to study inflammatory or pathological pain, but the use of animals also possesses ethical constraints and challenges [14]. Pha1 $\beta$ and recombinant CTK 01512-2 have been extensively studied in a wide range of rodent pain models (Table 1 ). This review focuses on persistent pathological pain models - cancer pain and neuropathic pain (NP) because these pain states are particularly challenging and can be effectively controlled by spider toxins.
The hot plate or tail-flick test represents models of acute thermal pain where no tissue injury occurs. Souza et al. [15] showed that i.t. delivery of Pha1 $\beta$ (200 $\mathrm{pmol} / \mathrm{site})$ produced a long-lasting ( 3 to $24 \mathrm{~h}$ after injection) antinociceptive action in the hot-plate test. The low potency of spider peptides in acute thermal tests $[15,16]$ can be considered a desirable effect that reflects the safety of the toxin. Acute thermal pain, as a nociceptive state, has an important physiological protective function in the preservation of living organisms, and its blockage should be avoided in some circumstances [11].

The formalin test is a preclinical test commonly used to track new compounds with analgesic potential [17-21]. Nociceptive behaviour triggered by formalin injection induces a biphasic behavioural response with a well-defined transition from acute pain to a more persistent pain state [21].

The effects of intrathecal administration of the toxin Pha1 $\beta$ on visceral pain (VP) induced by intraperitoneal (i.p.) injection of acetic acid, intracolonic administration of capsaicin, and cyclophosphamide (CPA)-induced haemorrhagic cystitis (HC) have been examined $[22,23]$. The examination of VP that is the most frequent type of pathological pain remains a challenge for physicians [24-28]. VP animal models have been associated with increases in TRPV1 expression [28-31], a decrease in voltagesensitive potassium currents, and enhanced expression and function of voltage-sensitive calcium currents [30,31]. Pha1 $\beta$ (50 $\mathrm{pmol} / \mathrm{site}$ ) i.t. pre-treatment inhibited the VP writhes induced by acetic acid or intracolonic behaviours evoked by capsaicin administration [22]. Pha1 $\beta$ (50 pmol/site) displayed significant inhibitory effects on HC-related nociception [23], demonstrating its analgesic potential in visceral pain management.

Incisional surgery in rats and mice produces a sensitive, reproducible, and quantifiable animal model of postoperative pain [32] that is similar to human postoperative pain syndrome in which the surgical incision causes mechanical allodynia and other pain behaviours [33,34]. Intrathecal injection of Pha1 $\beta$ reduced pain indicating behaviours in a mouse model of incisional pain when administered pre- or postoperatively $[35,36]$. Long-term antinociceptive action suggests that this toxin could also be a therapeutic agent for the control of persistent pain [37]. Numerous results $[15,22,23,35,36,37]$ suggest that spider toxin has the potential to be an efficient and safe alternative for the treatment of various nociceptive and inflammatory pain modalities.

\section{Pha1 $\beta$ antinociceptive effects in a cancer pain model}

Cancer-related pain is a prevalent and disabling symptom that requires early prevention and efficient treatment. Currently, opioids are practically the only analgesics capable of controlling severe cancer pain; however, opioid therapy leads to distinct side effects, including the development of analgesic tolerance, sedation, and gut constipation that limit their use $[36,38]$. Metastatic melanoma is associated with moderate and severe pain, and more than half of these patients require palliative care with morphine therapy [39]. By using an orthotopic tumour 
Table 1. Analgesic-like effects of Pha1 $\beta$, CTK 01512-2 and $\omega$-conotoxin MVIIA (Ziconotide, Prialt $®)$ in different models of rodent pain.

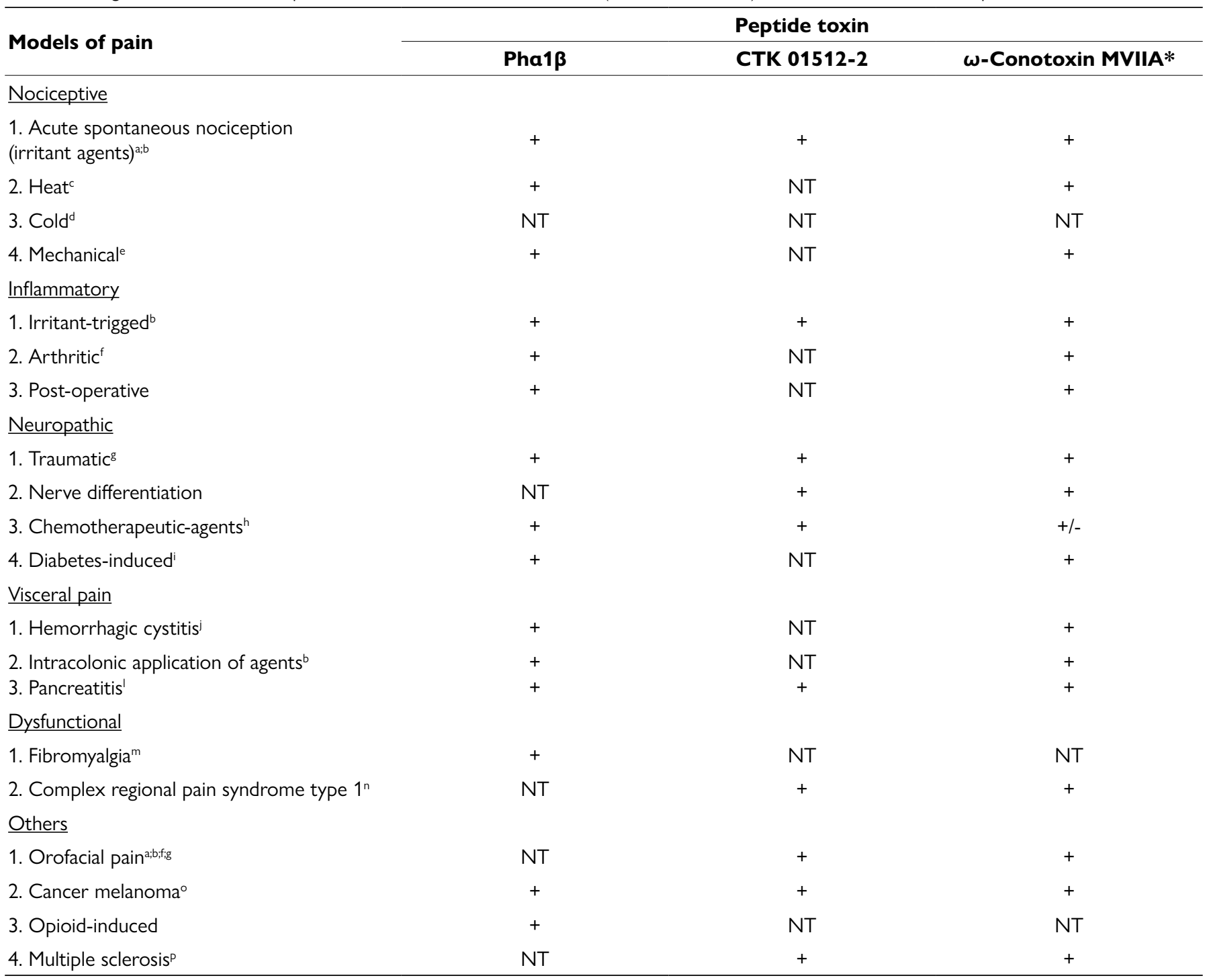

aFormalin; 'bapsaicin; chot plate; 'acetone or tetrafluoroethene; eVon Frey filaments; 'FFreund's complete adjuvant-induced inflammation; '8partial sciatic nerve ligation or chronic constriction injury; 'paclitaxel or bortezomib; 'streptozotocin-induced diabetes; 'cyclophosphamide; kacetic acid; 'caused by 5 times hourly cerulein treatment; ${ }^{\mathrm{m}}$ caused by repeated reserpine treatment; ${ }^{\mathrm{n}}$ exposure to prolonged hind paw ischemia and reperfusion; ${ }^{\circ} \mathrm{B} 16 \mathrm{~F} 10$ murine melanoma cells; ${ }^{\mathrm{P}} \mathrm{myelin}$ oligodendrocytes glycoprotein $\left(\mathrm{MOG}_{35-55}\right.$ )- induced. *Included as positive control; NT: not tested; +: effect; +/-: $\omega$-Conotoxin MVIIA presented effect in chemotherapy-induced neuropathic pain induced by paclitaxel but not in bortezomib, respectively.

inoculation model, Rigo et al. [36] developed a mouse model of skin melanoma that reproduced severe mechanical hyperalgesia in mice. Intrathecal treatment with Pha1 $\beta$ (30 pmol/site) in mice with melanoma remedied this hyperalgesia in a time and dose-dependent manner with an effect that lasted up to $6 \mathrm{~h}$, comparable to the effect of i.t. treatment with $\omega$-conotoxin MVIIA [36]. The development of analgesic tolerance is one of the most serious drawbacks of opioids when used repetitively [38]. Using a melanoma model of cancer-related pain in mice, Rigo et al. [36] reproduced an opioid-induced tolerance scenario by administering consecutive doses of morphine for three consecutive days [36]. On the fourth day, the injection of a new challenging dose of morphine was unable to reduce heat hyperalgesia, suggesting analgesic tolerance. Pha1 $\beta$ but not $\omega$-conotoxin MVIIA [40], administered $2 \mathrm{~h}$ before morphine restored the analgesic effect of this opioid. This suggests that Pha1 $\beta$ could potentially be used as an adjuvant drug for opioidbased cancer pain management. The effect of Pha1 $\beta$ on cancerrelated pain in mice was also reproduced with the recombinant form of the toxin [13].

\section{Pha1 $\beta$ antinociceptive effects in a surgically induced neuropathic pain model}

The role of VACC and their inhibitors in neuropathic pain mechanisms has been substantiated [41]. Many surgical animal models such as chronic constriction injury (CCI) of the sciatic nerve, partial sciatic nerve ligation ( $\mathrm{pSNL}$ ), spinal nerve ligation (SNL), spared nerve injury (SNI), brachial plexus avulsion (BPA), 
sciatic nerve transaction (SNT), and sciatic nerve trisection have been important in the development of chronic pain control. Evidence indicates that the principal pathogenic mechanisms responsible for the induction of neuropathic pain by CCI of the peripheral nerve are associated with oedema, ischemia, macrophage activation (myelin and axonal debris), endoneural extracellular matrix remodelling, cytokine and chemokine upregulation, and other manifestations of neuroinflammation [42-45]. In the pSNL model, i.t. injection of $30 \mathrm{pmol} / \mathrm{site}$ of Pha1 $\beta$ caused an anti-allodynic effect from 1 to $4 \mathrm{~h}$ after injection and did not alter the normal mechanical sensitivity of the animals [15]. The data from the CCI model showed that administration of Pha1 $\beta$ (200 pmol/site) in the lumbar subarachnoid space blocked the maintenance of mechanical allodynia for up to $4 \mathrm{~h}$ after the treatment, with an effect similar to that of $\omega$-conotoxin MVIIA [46]. Moreover, other studies demonstrated the anti-allodynic and anti-hyperalgesic effects of Pha1 $\beta$ after a single i.t. injection of 30 or 100 pmol per site in a rat model of neuropathic CCI $[15,46]$. Rats subjected to CCI were implanted with osmotic pumps delivering $60 \mathrm{pmol} / \mu \mathrm{L} / \mathrm{h}$ of Pha1 $\beta$ or saline placebo $(1.0 \mu \mathrm{L} / \mathrm{h})$ for 7 days [47]. After the initiation of spinal infusion of Pha1 $\beta$, a significant antihyperalgesic effect began after $24 \mathrm{~h}$ (inhibition of $63 \% \pm 13 \%$ ) and continued for 6 more days $90 \%$ of inhibition on the second day and $100 \%$ from day 3 to day 7 . Thus, Pha1 $\beta$ attenuated mechanical allodynia in the pSNL and CCI models because of decreased calcium influx into injured sensory neurons.

\section{Pha1 $\beta$ antinociceptive effects in a chemotherapy- induced neuropathic pain model}

Paclitaxel (a taxane-derived anticancer agent) causes peripheral sensory damage resulting in chemotherapy-induced neuropathic pain (CINP); in some patients, an acute pain syndrome appears in the early days of treatment [48]. The mechanism by which chemotherapeutics damage the nervous system and cause CINP is multifactorial and involves inhibition of tubulin dynamics that hampers axonal transport and can lead to axonopathy, loss of epidermal innervation $[49,50]$, oxidative stress, mitochondrial damage [51-54], altered ion channel activity [48,55,56], apoptosis [52], DNA and myelin sheath damage, immunological processes, and neuroinflammation $[53,57,58]$. The dysregulation of calcium homeostasis has been implicated in the causation of neuropathic pain [58-61].

In a model of paclitaxel-induced acute and chronic pain, Rigo et al. [37] evaluated the analgesic potential of two NVACC blockers, $\omega$-conotoxin MVIIA and Pha1 $\beta$. The spider toxin showed a superior therapeutic window compared to the $\omega$-conotoxin MVIIA. Pha1 $\beta$ reduced acute and chronic mechanical hyperalgesia induced by paclitaxel and prevented the worsening of the associated chronic pain. Therefore, VACC blockers such as Phal $\beta$ reduce synaptic excitation at the level of the spinal cord and could be helpful in the treatment of paclitaxel-induced CINP. TRPA1 expressed in sensory neurons has been shown to contribute to paclitaxel- induced neuropathic pain $[62,63]$. Pha1 $\beta$ selectively inhibits calcium influx and currents evoked by the TRPA1 agonist on hTRPA1-HEK293, IMR90 fibroblasts, and DRG neurons [12]. The mechanisms involved in the modulation of TRPA 1 channels may contribute significantly to acute and chronic cold allodynia and hyperalgesia induced by paclitaxel.

\section{Pha1 $\beta$ antinociceptive effects in diabetic europathic pain model}

Diabetic neuropathy (DN) is the most prevalent chronic complication of diabetes [64]. DN is primarily a disorder of sensory nerves; early in the course of DN, patients commonly experience positive sensory symptoms in the feet such as pain, tingling, and paraesthesia, and negative symptoms such as numbness. Disordered sensory processing may evoke allodynia and hyperalgesia [65]. The pathogenesis of DN is multifactorial, and the mechanisms contributing to diabetic DN are not completely understood [66]. It has been suggested that approximately $50 \%$ of adults with diabetes are affected by peripheral neuropathy throughout their lifetime [67]. DN induces upregulation of TNF- $\alpha$ and CXCR4 in the DRG at both the early and late phases of DN.

Pha1 $\beta$, $\omega$-conotoxin MVIIA, and AMD3100 (a selective antagonist of CXCR4) administered intrathecally $2 \mathrm{~h}$ after STZ-induced DN reduced hypersensitivity in diabetic rats and decreased calcium influx and IL-6 level in the spinal cord [68]. In naïve rats with CXCR4/SDF-1 activation, the induced hypersensitivity decreased after $2 \mathrm{~h}$ of treatment with Pha1 $\beta$ or AMD-3100, while $\omega$-conotoxin MVIIA did not affect i.t. [68]. The inhibitory effect of Pha1 $\beta$ toxin on diabetic neuropathic pain may involve the CXCR4 chemokine receptor in the spinal cord [68].

\section{Pha1 $\beta$ and ziconotide toxin safety profile}

Ziconotide ( $\omega$-conotoxin MVIIA) has been approved by the FDA for pain control. However, ziconotide has a narrow therapeutic window, producing maximal analgesia at doses close to the toxic dose, and causing severe side effects that limit its clinical use $[69,70,71]$. The $\mathrm{DT}_{50}$ of $\omega$-conotoxin MVIIA (ziconotide) is 287 (147-562) pmol/site and for Pha1 $\beta$ is 787 (485-1278) pmol/ site [15]. It is noteworthy that Ph $\alpha 1 \beta$ can produce maximal analgesia at doses that do not induce potential side effects. In contrast, the maximal analgesia induced by $\omega$-conotoxin MVIIA (ziconotide) could only be observed at doses close to $\mathrm{DT}_{50}$, causing severe side effects [15]. The therapeutic window $\left(\mathrm{DI}_{50} / / \mathrm{DT}_{50}\right)$ for Pha1 $\beta$ and $\omega$-conotoxin MVIIA are 16 and 4 , respectively [15]. The higher therapeutic window for Pha1 $\beta$ can be explained by several factors including binding to other types of VACC [10] and inhibition of cation channels such as TRPA1 receptors involved in several nociception processes [12].

Miljanich and Ramachandran [72] showed that intrathecal NVACC blockers such as ziconotide (a chemically synthesised version of Conus magus $\omega$-conotoxin MVIIA) induce clinical and behavioural effects (shaking behaviour, ataxia, and 
hyperreactivity) in the central nervous system (CNS) of rats, dogs, and monkeys. Similarly, clinical studies have reported several adverse effects caused by i.t. administration in humans including abnormal gait, ataxia, hypertonia, and tremor [73], with one of the main adverse effects being hypotension [70]. The intravenous (i.v). administration of ziconotide in rats and rabbits has been shown to cause hypotension and increased heart rate (HR) by a combination of sympathetic neurotransmission blockage and mast cell degranulation [74,75]. Currently, ziconotide is administered clinically by a continuous i.t. infusion in the therapeutic management of neuropathic pain, producing a marked analgesic effect in this difficult-to-treat condition [76-78]. Unfortunately, even at analgesic therapeutic doses, ziconotide causes serious side effects [9].

It has been demonstrated that Pha1 $\beta$ inhibits high voltageactivated calcium channels such as NVACC [10]. Our research group studied the possibility that i.t. Phal $\beta$ might cause cerebellar-related motor alterations since i.t. injection of $\mathrm{N}$ - and P-type calcium channel inhibitors in rats caused the serpentine tail movements and whole-body shaking [79]. After confirming its analgesic potential and safety compared with $\omega$-conotoxin MVIIA, the next step was an extensive evaluation of the cardiovascular profile and overall neurological behaviour. The $\mathrm{N}$-type calcium channel is a target for chronic and neuropathic pain [80]. The safety profile of i.t. Pha1 $\beta$ in relevant states of chronic pain has been assessed $[15,36,37]$ as well as the toxic effects of the native peptide after a single or continuous i.t. infusion in a rat model of neuropathic pain [47]. Recently, clinical signs, serum biochemistry, organ weight, and histopathological alterations were evaluated in male and/or female Wistar rats by searching for possible alterations caused by acute i.t. administration of Pha1 $\beta$ at a high dose [81]. Ph $\alpha 1 \beta$ i.t. injection produced maximum analgesia after doses (100-200 $\mathrm{pmol} / \mathrm{site}$ ) that did not induce the described potential side effects, with a therapeutic window of 16 [15]. Only dynamic allodynia was observed in an intrathecally delivered dose of $100 \mathrm{pmol}$ [13]. In comparison, the maximal analgesia induced by $\omega$-conotoxin MVIIA (100 pmol/site) could only be observed in doses that cause severe side effects with a therapeutic window of 4 [15].

The pre-clinical tests performed to establish a cardiovascular profile and overall neurological behaviour showed that i.t. Phal $\beta$ (200 pmol/site) did not change the mean arterial blood pressure or HR $3 \mathrm{~h}$ after the injection. However, i.t. $\omega$-conotoxin MVIIA (100 pmol/site) induced an increase in HR $3 \mathrm{~h}$ after administration [35]. Treatment with the toxin did not alter neurological performance after $3 \mathrm{~h}$, suggesting the absence of causing neurological deficits in rats [35]. Even in a paclitaxelinduced acute and chronic pain model, i.t. $\omega$-conotoxin MVIIA (10-100 pmol/site) caused adverse effects while Ph $\alpha 1 \beta$ (30-300 $\mathrm{pmol} / \mathrm{site}$ ) produced only minor adverse effects when injected at the acute or chronic pain stage [37]. The same results were reproduced in a cancer-related pain model; $\omega$-conotoxin MVIIA showed adverse effects (such as sedation, motor dysfunction, and paradoxical hyperalgesia) at all tested doses, while Pha1 $\beta$ produced minimal adverse effects (paradoxical hyperalgesia) only at the highest tested dose [37].

Continuous intrathecal infusion of an NVACC blocker is a critical option for neuropathic pain management [80]. The Pha1 $\beta$ 's antinociceptive and toxic effects were compared after a single continuous i.t. infusion in a rat model of NP induced by CCL of the sciatic nerve. A single injection of Pha1 $\beta$ (30 or $100 \mathrm{pmol} / \mathrm{site})$ or continuous infusion $(60 \mathrm{pmol} / \mu \mathrm{L} / \mathrm{h}$ for 7 days) was able to reverse nerve injury-induced nociception [47]. In both forms of administration, the toxin did not cause behavioural side effects or histopathological changes in the CNS. In a single or continuous injection, intrathecal administration of ziconotide causes nausea, confusion, postural hypotension, allodynia, abnormal gait, urinary retention, and weakness, and severe side effects that tend to occur more commonly at higher doses [73-78]. The detailed alterations related to the behavioural side effects are described in Table 2.

Dellagrave et al. [81] evaluated clinical signs, relative organ weight, biochemical parameters, and histopathological alterations in hepatic and renal tissues. Clinical signs manifested by Ph $\alpha 1 \beta$ (500 pmol/site) injected in male rats only showed dyspnoea, while females manifested decreased touch response and tremors. There were no significant differences in the weights of the male and female organs. Serum biochemical data in male rats revealed a significant reduction within the physiological limits of species related to urea, AST, ALT, ALP, and hepatic and renal congestion [81]. Evaluation of the potential cytotoxic, genotoxic, and mutagenic effects of Phal $\beta$ by different methods showed that Phal $\beta$ (500 pmol/site) induced DNA damage in the spinal cord but not in peripheral blood [82]. In conclusion, the native toxin showed a good safety profile with transient signs of clinical toxicity [81] and genotoxic effects only in SNC [82] at doses five times higher than those used to obtain the analgesic effect. The results demonstrate that $\mathrm{Ph} \alpha 1 \beta$ produces analgesia after single or continuous i.t. delivery in relevant models of acute and chronic pain eliciting minimal toxic effects and with a greater therapeutic window of 16, higher than that 4 of $\omega$-conotoxin MVIIA [15].

\section{Pha1 $\beta$ toxin action mechanisms}

Phal $\beta$ toxin has been proven to inhibit HVA calcium channels and act as a TRPA1 antagonist. This inhibitory effect is most useful in controlling pain due to the overexpression or increased activity of the molecular agents in these disease conditions. Spider peptide activity on the nervous system has been extensively investigated through events related to high-voltage activated calcium channels (HVACC) and TRPs such as intracellular calcium transients, neurotransmitter release, oxidative stress pathways, and inflammatory mediators (Table 3 ). This review focuses on the effects of Pha1 $\beta$ on molecular targets, calcium influx, glutamate release, and reactive oxygen species (ROS) generation as the most important and described mechanisms related to pain pathways. Glial plasticity effects have also been reported and are detailed in Table 3. 
Table 2. Side effects of Pha1 $\beta$, CTK 01512-2 and $\omega$-conotoxin MVIIA (Ziconotide, Prialt $\AA$ ) in different doses or administration routes.

\begin{tabular}{|c|c|c|c|c|c|c|c|c|c|c|c|c|c|c|c|c|}
\hline \multirow{3}{*}{ 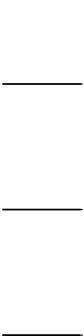 } & \multirow{3}{*}{$\begin{array}{c}\begin{array}{c}\text { Peptide } \\
\text { toxin }\end{array} \\
\text { Routes } \\
\text { Doses }\end{array}$} & \multicolumn{6}{|c|}{ Pha1ß } & \multicolumn{6}{|c|}{ CTK 01512-2 } & \multirow{2}{*}{\multicolumn{3}{|c|}{$\begin{array}{c}\text { w-Conotoxin } \\
\text { MVIIA* }\end{array}$}} \\
\hline & & \multicolumn{5}{|c|}{$\begin{array}{l}\text { Intrathecal } \\
\text { route }\end{array}$} & \multirow{2}{*}{$\begin{array}{c}\begin{array}{c}\text { Intrathecal } \\
\text { continuous } \\
\text { infusion }\end{array} \\
60 \\
\text { pmol/ul/h }\end{array}$} & \multicolumn{3}{|c|}{$\begin{array}{l}\text { Intrathecal } \\
\text { route }\end{array}$} & \multicolumn{3}{|c|}{$\begin{array}{l}\text { Intravenous } \\
\text { route }\end{array}$} & & & \\
\hline & & $\begin{array}{c}10 \\
\text { pmol/ } \\
\text { site }\end{array}$ & $\begin{array}{c}30 \\
\text { pmol/ } \\
\text { site }\end{array}$ & $\begin{array}{c}100 \\
\text { pmol/ } \\
\text { site }\end{array}$ & $\begin{array}{c}200 \\
\text { pmol/site }\end{array}$ & $\begin{array}{c}300 \\
\text { pmol/ } \\
\text { site }\end{array}$ & & $\begin{array}{c}30 \\
\text { pmol/ } \\
\text { site }\end{array}$ & $\begin{array}{l}100 \\
\mathrm{pmol} / \\
\text { site }\end{array}$ & $\begin{array}{l}200 \\
\mathrm{pmol} / \\
\text { site }\end{array}$ & $\begin{array}{c}0.2 \\
\mathrm{mg} / \mathrm{kg}\end{array}$ & $\begin{array}{c}0.6 \\
\mathrm{mg} / \mathrm{kg}\end{array}$ & $\begin{array}{c}1.8 \\
\mathrm{mg} / \mathrm{kg}\end{array}$ & $\begin{array}{c}10 \\
\mathrm{pmol} / \\
\text { site }\end{array}$ & $\begin{array}{c}30 \\
\mathrm{pmol} / \\
\text { site }\end{array}$ & $\begin{array}{c}100 \\
\text { pmol/ } \\
\text { site }\end{array}$ \\
\hline \multirow{8}{*}{ 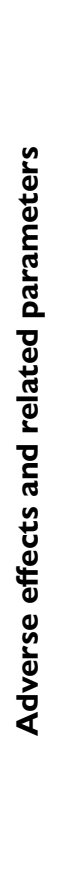 } & $\begin{array}{c}\text { Serpentine } \\
\text { tail }\end{array}$ & Absent ${ }^{r}$ & Absent ${ }^{r}$ & Absent $^{r m}$ & Absent $^{m}$ & Absent ${ }^{r}$ & Absent ${ }^{r}$ & Absent $^{m}$ & Absent $^{\mathrm{m}}$ & $\begin{array}{l}\text { Not } \\
\text { tested }\end{array}$ & Absent $^{\mathrm{m}}$ & Absent $^{m}$ & Absent $^{m}$ & Present $^{r m}$ & Absent $^{r m}$ & Absent $^{r m}$ \\
\hline & Body shake & Absent ${ }^{r}$ & Absent ${ }^{r}$ & Absent ${ }^{r m}$ & Absent $^{m}$ & Absent ${ }^{r}$ & Absent $^{r}$ & Absent $^{m}$ & Absent $^{m}$ & $\begin{array}{l}\text { Not } \\
\text { tested }\end{array}$ & Absent $^{m}$ & Absent $^{m}$ & Absent $^{m}$ & Present $^{r m}$ & Absent $^{r m}$ & Present $^{r m}$ \\
\hline & $\begin{array}{l}\text { Dynamic } \\
\text { allodynia }\end{array}$ & Absent ${ }^{r}$ & Absent ${ }^{r}$ & Present $t^{r m}$ & Absent $^{\mathrm{m}}$ & Absent ${ }^{r}$ & Absent ${ }^{r}$ & Absent $^{m}$ & Present $^{m}$ & $\begin{array}{l}\text { Not } \\
\text { tested }\end{array}$ & Absent $^{m}$ & Absent $^{m}$ & Absent $^{m}$ & Present $^{r m}$ & Present $^{r m}$ & Present $t^{r m}$ \\
\hline & Sedation & $\begin{array}{l}\text { Not } \\
\text { tested }\end{array}$ & Absent $^{m}$ & Absent $^{m}$ & $\begin{array}{l}\text { Not } \\
\text { tested }\end{array}$ & $\begin{array}{l}\text { Not } \\
\text { tested }\end{array}$ & $\begin{array}{l}\text { Not } \\
\text { tested }\end{array}$ & $\begin{array}{l}\text { Not } \\
\text { tested }\end{array}$ & $\begin{array}{l}\text { Not } \\
\text { tested }\end{array}$ & $\begin{array}{l}\text { Not } \\
\text { tested }\end{array}$ & $\begin{array}{l}\text { Not } \\
\text { tested }\end{array}$ & $\begin{array}{l}\text { Not } \\
\text { tested }\end{array}$ & $\begin{array}{l}\text { Not } \\
\text { tested }\end{array}$ & $\begin{array}{l}\text { Not } \\
\text { tested }\end{array}$ & Present $^{r m}$ & Present ${ }^{r m}$ \\
\hline & $\begin{array}{c}\text { **Forced } \\
\text { motor } \\
\text { activity } \\
\text { impairment }\end{array}$ & $\begin{array}{l}\text { Not } \\
\text { tested }\end{array}$ & $\begin{array}{l}\text { Not } \\
\text { tested }\end{array}$ & Absent $^{m}$ & Absent $^{m}$ & $\begin{array}{l}\text { Not } \\
\text { tested }\end{array}$ & $\begin{array}{l}\text { Not } \\
\text { tested }\end{array}$ & $\begin{array}{l}\text { Not } \\
\text { tested }\end{array}$ & Absent $^{m}$ & $\begin{array}{l}\text { Not } \\
\text { tested }\end{array}$ & Absent $^{m}$ & $\begin{array}{l}\text { Not } \\
\text { tested }\end{array}$ & $\begin{array}{l}\text { Not } \\
\text { tested }\end{array}$ & Absent $^{m}$ & $\begin{array}{l}\text { Not } \\
\text { tested }\end{array}$ & $\begin{array}{l}\text { Not } \\
\text { tested }\end{array}$ \\
\hline & $\begin{array}{c}* * * \text { General } \\
\text { motor } \\
\text { activity } \\
\text { impairment }\end{array}$ & $\begin{array}{l}\text { Not } \\
\text { tested }\end{array}$ & $\begin{array}{l}\text { Not } \\
\text { tested }\end{array}$ & Absent $^{m}$ & Absent ${ }^{r m}$ & $\begin{array}{l}\text { Not } \\
\text { tested }\end{array}$ & $\begin{array}{l}\text { Not } \\
\text { tested }\end{array}$ & $\begin{array}{l}\text { Not } \\
\text { tested }\end{array}$ & Absent $^{m}$ & Absent ${ }^{r}$ & $\begin{array}{l}\text { Not } \\
\text { tested }\end{array}$ & $\begin{array}{l}\text { Not } \\
\text { tested }\end{array}$ & $\begin{array}{l}\text { Not } \\
\text { tested }\end{array}$ & Absent $^{m}$ & $\begin{array}{l}\text { Not } \\
\text { tested }\end{array}$ & Absent ${ }^{r}$ \\
\hline & $\begin{array}{c}\text { Mean } \\
\text { arterial } \\
\text { pressure }\end{array}$ & $\begin{array}{l}\text { Not } \\
\text { tested }\end{array}$ & $\begin{array}{l}\text { Not } \\
\text { tested }\end{array}$ & $\begin{array}{l}\text { Not } \\
\text { tested }\end{array}$ & Unaffectedr & $\begin{array}{l}\text { Not } \\
\text { tested }\end{array}$ & $\begin{array}{l}\text { Not } \\
\text { tested }\end{array}$ & $\begin{array}{l}\text { Not } \\
\text { tested }\end{array}$ & $\begin{array}{l}\text { Not } \\
\text { tested }\end{array}$ & $\begin{array}{l}\text { Not } \\
\text { tested }\end{array}$ & \multicolumn{3}{|c|}{ Unaffected $^{m}$ Unaffected $^{m}$ Unaffected $^{m}$} & $\begin{array}{l}\text { Not } \\
\text { tested }\end{array}$ & $\begin{array}{l}\text { Not } \\
\text { tested }\end{array}$ & $\begin{array}{l}\text { Not } \\
\text { tested }\end{array}$ \\
\hline & $\begin{array}{c}\text { Heart } \\
\text { frequency }\end{array}$ & $\begin{array}{l}\text { Not } \\
\text { tested }\end{array}$ & $\begin{array}{l}\text { Not } \\
\text { tested }\end{array}$ & $\begin{array}{l}\text { Not } \\
\text { tested }\end{array}$ & Unaffected ${ }^{r}$ & $\begin{array}{l}\text { Not } \\
\text { tested }\end{array}$ & $\begin{array}{l}\text { Not } \\
\text { tested }\end{array}$ & $\begin{array}{l}\text { Not } \\
\text { tested }\end{array}$ & $\begin{array}{l}\text { Not } \\
\text { tested }\end{array}$ & $\begin{array}{l}\text { Not } \\
\text { tested }\end{array}$ & \multicolumn{3}{|c|}{ Unaffected $^{m}$ Unaffected $^{m}$ Unaffected $^{m}$} & $\begin{array}{l}\text { Not } \\
\text { tested }\end{array}$ & $\begin{array}{l}\text { Not } \\
\text { tested }\end{array}$ & $\begin{array}{l}\text { Not } \\
\text { tested }\end{array}$ \\
\hline
\end{tabular}

rRats; ${ }^{m}$ mice. *Included as a positive control for Pha1 $\beta$ and CTK 01512-2- studies from other groups were not considered; **evaluated by the Rotarod method; ***evaluated by the open field method. 
Table 3. Pha1 $\beta$, CTK 01512-2 and $\omega$-conotoxin MVIIA (Ziconotide, Prialt $\AA$ ) pain pathway action mechanisms.

\begin{tabular}{|c|c|c|c|}
\hline \multirow{2}{*}{ Action mechanisms } & \multicolumn{3}{|c|}{ Peptide toxin } \\
\hline & Pha1 $\beta$ & CTK 01512-2 & $\omega$-Conotoxin MVIIA* \\
\hline Molecular targets & & $\mathrm{IC}_{50}(\mathrm{nM})$ & \\
\hline \multicolumn{4}{|l|}{ Voltage gated calcium channel $^{\mathrm{a}}$} \\
\hline 1. N-type VACC & 122 & Not tested & Not tested \\
\hline 2. R- type VACC & 136 & Not tested & Not tested \\
\hline 3. P/Q - type VACC & 263 & Not tested & Not tested \\
\hline 4. L - type VACC & 607 & Not tested & Not tested \\
\hline 5. T - type VACC & Not tested & Not tested & Not tested \\
\hline \multicolumn{4}{|l|}{$\underline{T r a n s i e n t ~ r e c e p t o r ~ p o t e n t i a l a ~}^{\mathrm{a} ; \mathrm{b} ; \mathrm{c}}$} \\
\hline 1. TRPV1 & Unaffected & Unaffected & Not tested \\
\hline 2. TRPV4 & Unaffected & Unaffected & Not tested \\
\hline 3. TRPA1 & $681^{\mathrm{a}} ; 40^{\mathrm{b}} ; 32^{\mathrm{c}}$ & $506^{a} ; 28^{b} ; 34^{c}$ & Not tested \\
\hline \multicolumn{4}{|c|}{ Molecular targets related events } \\
\hline Intracellular $\mathrm{Ca}^{2+}$ & Decrease $^{c_{\mathrm{c} ; \mathrm{j} ;}}$ & Decrease $^{\mathrm{c} ; \mathrm{d} ; \mathrm{e}}$ & Decrease $^{c_{i}}$ \\
\hline Glutamate release & Decrease $e^{\text {eff }}$ & Decrease $e^{\text {f:g }}$ & Decrease $e^{\text {effig }}$ \\
\hline \multicolumn{4}{|l|}{ Oxidative stress } \\
\hline 3.1 ROS generation & Decrease $^{f}$ & Not tested & Decrease $^{f}$ \\
\hline 3.2 Lipid peroxidation & Not tested & Decrease $^{c}$ & Decrease ${ }^{c}$ \\
\hline 3.3 Myeloperoxidase activity & Decrease $\mathrm{e}^{\mathrm{e} h \mathrm{~h}}$ & Not tested & Unaffected ${ }^{\text {e; }}$ \\
\hline 3.4 Malondialdehyde levels & Decrease $^{e}$ & Not tested & Not tested \\
\hline \multicolumn{4}{|l|}{$\underline{\text { Inflammatory mediators }}$} \\
\hline 4.1 TNF-a & Decrease ${ }^{i}$ & Decrease $\mathrm{e}^{\mathrm{e} h \mathrm{~h}}$ & unaffected; ;i \\
\hline $4.2 \mathrm{IL}-1 \beta$ & Decrease $^{i}$ & Decrease $e^{e / h}$ & Decrease $\mathrm{e}_{\mathrm{e}, \mathrm{h} ; \mathrm{i}}$ \\
\hline $4.3 \mathrm{IL}-6$ & Decrease $^{\mathrm{a}}$ & Not tested & Decrease $^{\mathrm{a}}$ \\
\hline $4.4 \mathrm{IL}-10$ & Increase ${ }^{i}$ & Increase ${ }^{e: h}$ & Unaffected ${ }^{\text {eih;i }}$ \\
\hline \multicolumn{4}{|l|}{ Glial plasticity $^{\mathrm{e}}$} \\
\hline 5.1 GFAP & Decrease & Decrease & Decrease \\
\hline $5.2 \mathrm{lba}-1$ & Unaffected & Unaffected & Unaffected \\
\hline 5.3 Microglia proliferation & Decrease & Not tested & Not tested \\
\hline 5.4 Astrocyte proliferation & Decrease & Not tested & Not tested \\
\hline
\end{tabular}

aHuman embryonic kidney (HEK) 293 cells and N18 neuroblastoma cells; ${ }^{b}$ IMR90 cells; 'DRG neurons; ${ }^{\mathrm{d}}$ TRPA1-HEK293; ${ }^{\mathrm{e}}$ Spinal cord samples; ${ }^{\mathrm{f} C S F}$; ${ }^{\text {thrigeminal }}$ ganglia; 'brain tissue; 'bladder, 'paw skin. *Included as a positive control for Pha1 $\beta$ and CTK 01512-2 studies from other groups were not considered. Note: VACCs are shown in order of preference for Pha1ß.

\section{High voltage-activated calcium channel blockade by Pha1 $\beta$ toxin}

The activity of HVACC in different types of pain derives from their heterogeneity in structure, and tissue and cell localisation [83]. The calcium channel family consists of different channel subtypes that can be divided based on the voltage dependence of activation: HVA calcium channels into L-type ( $\left.\mathrm{Ca}_{\mathrm{v}} 1.1-\mathrm{Cav1.4}\right)$, P/Q-type ( $\left.\mathrm{Ca}_{\mathrm{v}} 2.1\right)$, N-type (Ca 2.2$)$, R-type (Ca 2.3$)$, and lowvoltage activated channels, T-type (Ca $\left.3.1, \mathrm{Ca}_{\mathrm{v}} 3.2, \mathrm{Ca}_{\mathrm{v}} 3.3\right)$ [84]. There is literature evidence implicating low-voltage calcium channel in pain pathologies [84] and Pha1 $\beta$ was no tested on the low-voltage activated channels. The NVACC are almost exclusively expressed in neuronal tissue and localised in synaptic nerve terminals in laminae 1 and 2 of the dorsal horn, where their opening results in the release of neurotransmitters such as CGRP, glutamate, and substance P $[84,85]$. Consequently, inhibiting calcium influx in the $\mathrm{Ca}_{\mathrm{v}} 2.2$ channel results in reduced neurotransmission and analgesia. Therefore, these calcium entry pathways are targets for therapeutic agents in the treatment of disorders such as pain management [86].

Vieira et al. [87] demonstrated that Pha1 $\beta$ inhibits calcium influx and decreases glutamate $\mathrm{Ca}^{2+}$-dependent exocytosis from cortical synaptosomes, suggesting that the toxin targets calcium channels. Electrophysiological recordings show that Pha1 $\beta$ blocks mammalian calcium ion currents in HVA calcium channels exogenously expressed in HEK cells [10]. Four HVA 
calcium channels were examined in this study; the blockade by Pha1 $\beta$ was the most potent and effective on $\mathrm{Ca}_{\mathrm{v}} 2.2$ (N-type voltage-activated calcium channels), blocking $>95 \%$. In addition to the blockade of Cav 2.2 channel, Pha1 $\beta$ partially reduced the conductance of $\mathrm{Ca}_{\mathrm{v}} 1$ (L-type), $\mathrm{Ca}_{\mathrm{v}} 2.1$ (P/Q-type), and $\mathrm{Ca}_{\mathrm{v}} 2.3$ subtypes (R-type). The suggested mechanism of action of Pha1 $\beta$ in calcium channel blockade is the complete blockade of $\mathrm{Ca}_{\mathrm{v}} 2.2$ currents. It seems that the native peptide may bind tightly to the external mouth of the channel and physically occlude the pores. When Pha1 $\beta$ action on Cav1, Cav2.1, and Cav2.3 subtypes was evaluated, an incomplete blockade was observed, suggesting that the Pha1 $\beta$ effect might be associated with a state-dependent affinity between the channel and the toxin [10]. Literature reports that several blockers of voltage-activated $\mathrm{Ca}^{2+}$ channels exhibit state and/or potential-dependent blockage [88-89]. However, Pha1 $\beta$ was tested at concentrations up to $1 \mu \mathrm{M}$; thus, higher concentration of the toxin may achieve the complete blockage of these channels. The order of potency of Pha1 $\beta$ inhibition on calcium currents was N-(a1B/Cav2.2) > R-(a1E/Cav2.3) > P/Q(a1A/Cav2.1) > L-(a1C/Cav1.2) [10]. Therefore, Pha1 $\beta$ exhibited a measurable preference for $\mathrm{Ca}_{\mathrm{v}} 2.2$ calcium channel, with the blockade being reversible. These results showed that blockade of NVACCs has pharmacological utility in the management of pain.

\section{TRPA1 channel antagonism by Pha1ß}

TRPA1 is a nonselective cation channel expressed in nociceptive somatosensory neurons of the DRG, trigeminal, and nodose sensory ganglia, acting as a cellular sensor to several harmful physical and chemical stimuli [90-91]. This channel is a member of a subset of transient receptor potential (TRP) channels subdivided into seven main subfamilies according to their homology and channel function: TRPC (canonical), TRPV (vanilloid), TRPM (melastatin), TRPML (mucolipin), TRPP (polycystin), TRPA (ankyrin transmembrane protein), and TRPN (Nom PC-like) [92]. This receptor can be activated and modulated by endogenous agonists derived from inflammatory or tissue injury conditions, thus contributing decisively to the pathogenesis of inflammation and pain, possibly in the transition from acute to chronic pain [92-93]. Studies involving the TRPA1 receptor have been carried out to develop new therapeutic tools for the treatment of pain. Tonello et al. [12] demonstrated that Pha1 $\beta$ inhibits HC-030031 (a TRPA1 receptor antagonist) and currents evoked by TRPA1 channel stimulation in HEK293 cell cultures (Figure 1). Pha1 $\beta$ reduced nocifensive responses evoked by allyl isothiocyanate, a TRPA1 agonist, by intraplantar and i.t. administration, attenuating mechanical and cold hyperalgesia in a model of NP pain induced by bortezomib. This study also showed that the recombinant peptide did not exert action on other TRP channels such as TRPV1 and TRPV4, suggesting its selectivity by the TRPA1 channel [12]. Previous findings have demonstrated that Ph $1 \beta$ does not inhibit the TRPV1 channel, corroborating the fact that this toxin does not affect other TRP channels [94].

\section{Reduced glutamate release by Pha1 $\beta$ toxin}

$\mathrm{N}$-type calcium channels are preferentially coupled to glutamate release in the enhanced nociceptive transmission at the spinal level following formalin inflammation [95]. Pha1 $\beta$ and $\omega$-conotoxin MVIIA blocked glutamate release evoked by capsaicin in isolated nerve terminals from the spinal cord, but Pha1 $\beta$ 's potency was about two times greater than that of $\omega$-conotoxin MVIIA [15]. The $\mathrm{IC}_{50}$ for the inhibitory effect on glutamate release on the nerve terminal by Pha1 $\beta$ was $2.1 \mu \mathrm{mol}$ while for $\omega$-conotoxin MVIIA it was $4.8 \mu \mathrm{mol}$ [15]. It is noteworthy that different pain models increase Glu levels in the cerebrospinal fluis (CSF) [15,95-98]. The antinociceptive and adverse effects produced by the native toxin form were fully mimicked by the CTK 01512 2 recombinant version in several pain models [13] (Figure 1). Moreover, in isolated nerve terminals obtained from the spinal cord, the spider toxin also blocked Glu release evoked by capsaicin [15]. Vieira et al. [87] demonstrated that Pha1 $\beta$ inhibits calcium

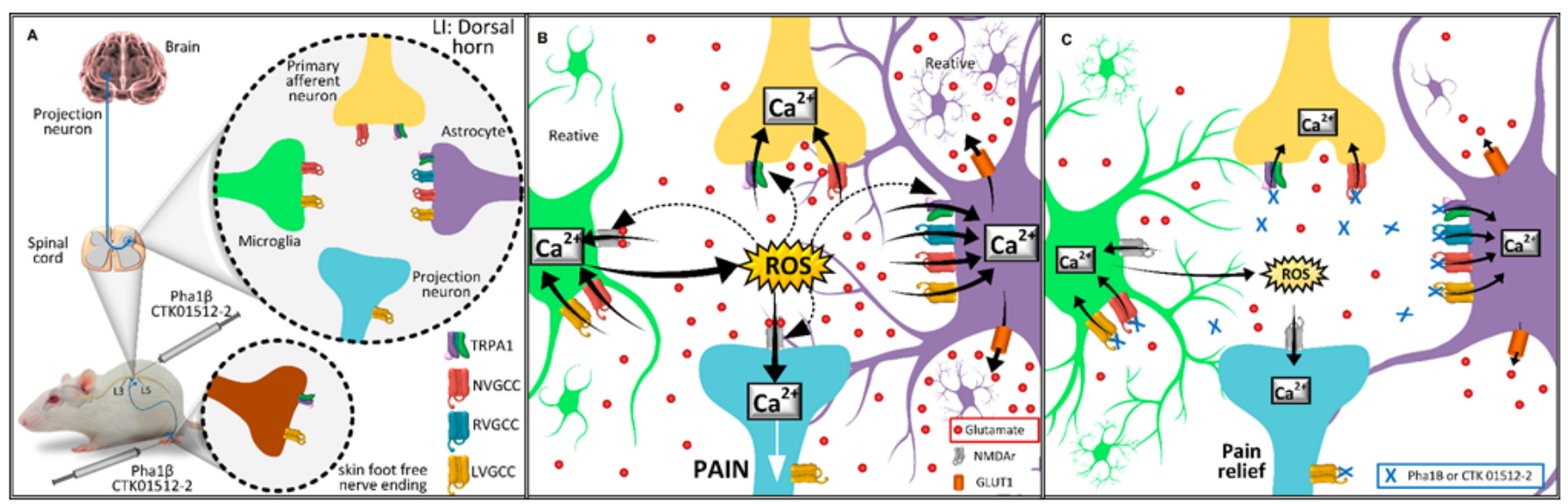

Figure 1. Molecular targets and action mechanisms involved in the intrathecal injection of Pha1 $\beta$ and CTK 01512-2 peptide. (A) Molecular targets of Pha1 $\beta$ and CTK 01512-2 and their cellular localization on the periphery tissue and lamina I of the spinal cord. (B) Pha1 $\beta$ and CTK 01512-2's molecular target activation related events in spinal cord lamina I during pain states. (C) The suggested mechanism for pain relief through molecular targets blockade by Pha1 $\beta$ and CTK 01512-2. Note: more studies are necessary to understand how native peptides and their recombinant versions interact with HVCACC and TRPA1. 
influx and decreases glutamate $\mathrm{Ca}^{2+}$-dependent exocytosis from cortical synaptosomes, suggesting that the toxin targets calcium channels. We believe that a reduction in excitatory neurotransmitter release from presynaptic terminals by decreasing calcium influx would lessen the activity of the dorsal horn neurons and thus raise the threshold for nociceptive response.

\section{Reduced reactive oxygen species generation by Pha1 $\beta$ toxin}

Several studies have demonstrated that increased intracellular $\mathrm{ROS}$, reactive nitrogen species (RNS), and $\mathrm{Ca}^{2+}$ play a major role in the aetiology of pain processes $[99,100]$. Interactions between ROS and calcium signalling can be considered as bidirectional, wherein ROS can regulate cellular calcium signalling, while calcium signalling is essential for ROS production [101]. Therefore, the elevation of intracellular calcium levels is responsible for the activation of ROS-generating cytosolic enzymes and the formation of free radicals by the mitochondrial respiratory chain. In contrast, ROS can significantly affect calcium influx into cells and intracellular calcium stores [102].

Some studies have reported that excessive ROS and RNS production in rat models involves TRPA1 channels in the aetiology of pain processes [103]. The cellular mechanisms have not been fully clarified, although there are some reports on TRPA1 activation-induced pain processes such as diabetic peripheral pain $[104,105]$, spinal cord injury-induced pain [106,107], and chemotherapeutic agent-induced pain [108]. Furthermore, sodium channel blockers reduce the influx of calcium into the cells, thereby reducing the production of free radicals and attenuating lipid peroxidation reactions [109]. This evidence suggests that this crosstalk between calcium influx and ROS/RNS generation plays an essential role in many pathophysiological conditions including neurodegenerative diseases such as Parkinson's, Alzheimer's, and inflammatory diseases [101], and neuropathic pain [110].

The effects of Phal $\beta$ on the generation of ROS and proinflammatory mediators have been observed in pain models $[22,23]$ (Figure 1). In the VP intracolonic capsaicin model, $\omega$-conotoxin MVIIA attenuation of depolarization-induced $\mathrm{Ca}^{2+}$ influx, specifically in NVACC, was less effective than Ph $\alpha 1 \beta$ in reducing ROS levels [22]. The higher effect of Ph $\alpha 1 \beta$ is most likely due to its HVA calcium channel current inhibition [10] and TRPA1 channel blockade [12]. The marked analgesic, antiinflammatory, and recovery of functional actions promoted by Pha1 $\beta$ appear to rely on the reduction of neutrophil migration that in turn might reduce oxidative stress.

\section{Glial structural plasticity reversal by Pha1 $\beta$ toxin}

The pain process and glial activation are directly related $[111,112]$. Proinflammatory molecules released at the injury site can stimulate sensory neurons in the peripheral terminal and release several pro-algesic substances [113]. We found that CFA-induced hind paw inflammation in rats produced robust morphological changes in spinal astrocytes and microglia, compatible with the reactive phenotype [114]. These glial changes include an increase in GFAP protein expression in astrocytes [115-117] and Iba1 or OX-42 proteins in microglia [118-121].

In addition to its analgesic properties, the Pha1 $\beta$ spider toxin reverses glial changes caused by peripheral inflammation [115], reducing the overexpression of GFAP and Ibal in short-time astrogliosis (2 days) and long-term microgliosis (14 days). These effects were more apparent in rats treated with the Ph $\alpha \beta$ spider toxin than with $\omega$-conotoxin MVIIA, a specific N-type calcium channel antagonist. Microglia proliferation induced by CFA peripheral inflammation was not observed. Intriguingly, treatment with $\omega$-conotoxin MVIIA toxin produced a significant increase in microglia proliferation [115]. Microglial cells express a myriad of receptors such as calcium channels [122,123]. Glial plasticity depends on intracellular and extracellular calcium signalling which is important for regulating glial autocrine signalling, structural plasticity, and proliferation [124,125]. Phal $\beta$ might exert an effect on glial calcium channels because of its ability to act as a VACC inhibitor. However, it is still unclear whether Pha1 $\beta$ toxin acts directly or indirectly in glial cells.

\section{Recombinant CTK 01512-2 shows effects similar to the native Pha $\beta$ toxin}

The development of the recombinant version of Pha1 $\beta$ named CTK 01512-2 arose because of the difficulty of getting significant amounts of spider venom and obtaining the native toxin by purifying spider venom. Giotto Biotech S.r.l. (Florence, Italy) synthesised this recombinant form through expression in Escherichia coli. The CTK 01512-2 have an identical sequence of the 55 amino acids as the native Phal $\beta$ toxin (ACIPRGE ICTDDCECCGCDNQCYCPPGSSLGIFKCSCAHANKYFCNR KKEKCKK) and six disulphide bonds [126]. The recombinant peptide showed strong analgesic activity as the native toxin, with negligible side effects [13]. It reduced mechanical hyperalgesia induced by $\mathrm{CCl}$ in the sciatic nerve [13]. In a deafferentation pain model, CTK 01512-2 attenuated mechanical allodynia, cold allodynia, and thermal hyperalgesia without affecting the locomotor and exploratory activity of the rats [127]. Orofacial pain is a painful condition that affects the soft and hard tissues of the head, face, and neck $[128,129]$. CTK 01512-2 reduced orofacial hyperalgesia in the formalin-induced inflammatory phase in the lip and intraarticular CFA injections [130].

The recombinant Pha1 $\beta$ showed a marked antiproliferative effect on glioblastoma cells after i.t. administration blocking NVACC [131], anti-hyperalgesic effects on cancer melanoma cells [36], and inhibition of capsaicin nociceptive behaviour [37]. Intrathecal treatment with recombinant peptides also modulates other events such as neuroinflammation and neurodegeneration $[132,133]$. In addition to pain signalling, there is evidence that VACC also participate in the development of some CNS disorders. In the model of experimental autoimmune encephalomyelitis (EAE) induced by myelin oligodendrocyte glycoprotein 
$\left(\mathrm{MOG}_{35-55}\right)$, the recombinant peptide administered i.t. showed antinociceptive activity [132], improving cognitive deficits and motor coordination, modulating the disease progression, and attenuating neuroinflammatory changes with higher efficacy than ziconotide and fingolimod [132]. Notably, i.v CTK 01512-2 attenuated the symptoms of the EAE model, while $\omega$-conotoxin MVIIA did not by this administration route [132]. CTK-01512-2 significantly improved the neuroinflammatory response in this model of multiple sclerosis (MS), reducing the levels of TNF, IL-1B, IFN- $\gamma$, IL-17, and IL-23 in the brain and spinal cord. These results indicate that the recombinant CTK-01512-2 greatly improved the neuroinflammatory responses with higher efficacy when compared to ziconotide, suggesting that this molecule is a promising adjuvant for MS management.

Acute pancreatitis (AP) is an inflammatory disease of the pancreas. Agents that modulate the activity of high-voltage activated calcium channels such as Pha1 $\beta$ [10] and $\omega$-conotoxin MVIIA [70,78] exhibit experimentally and clinically significant effects by relieving chronic pain in AP. In rodents, i.p. injections of cerulein induces AP as evidenced by an increase in hyperalgesic pain, inflammatory infiltration, amylase and lipase secretion, and reactive oxygen species formation [133]. Pha1 $\beta$ and its recombinant CTK 01512-2 form, both blockers of the TRPA1 receptor [12] and HVACC [10], abolished these effects [133] after i.t. administration. $\omega$-Conotoxin MVIIA, a selective inhibitor of N-type HVACC [72], did not affect the induced increase in pancreatic enzyme secretion. Ph $1 \beta$ has been shown to have an antinociceptive effect in several rodent pain models, including visceral pain [22], postsurgical, inflammatory, and neuropathic pain $[15,37,47]$, and cancer pain [36]. Intrathecal treatment with Pha1 $\beta$ and recombinant CTK 01512-2 did not significantly alter the spontaneous locomotion of rats with AP, whereas $\omega$-conotoxin MVIIA did affect it. These results suggest the potential use of Pha1 $\beta$ and recombinant CTK 01512-2 as analgesic drugs for the treatment of acute pancreatitis.

The analgesic and side effects of i.v. administered CTK 015122 were also studied in the CCL-induced neuropathic pain and paclitaxel-induced acute and chronic pain in which the recombinant toxin exerted analgesic action. The analgesic effects were not accompanied by acute toxicity compared to morphine that induced significant changes in motor activity, HR, and blood pressure [134]. The analgesic effect was also elicited in male and female mice by CTK 01512-2 (0.06 and 0.6 $\mathrm{mg} / \mathrm{kg}$ i.v) in a complex regional pain syndrome 1 model; the peptide attenuated mechanical and cold allodynia in the acute and chronic nociceptive state [135].

CTK 015122 is a selective antagonist of the TRPA1 channel as its natural toxin [12], producing in vivo peripheral and central antinociceptive effects via TRPA1 channel antagonism without affecting other TRP channels such as TRPV1 and TRPV4 [94].

The effect of CTK 015122 on glutamate levels, ROS generation, lipid peroxidation, DNA damage, and inflammatory mediators have been observed in pain models. Future studies are required to confirm that the recombinant peptide has potential for clinical use.

\section{Pha1 $\beta$ and CTK 01512-2 peptides as potential drugs for multimodal analgesia}

Studies addressing the analgesic potential of opioids combined with calcium channel blockers are scarce. In terms of opioid addiction, it has been estimated that more than 2 million people suffer from opioid-related substance abuse disorders [136]. The management of pain in opioid-tolerant patients is one of the most challenging aspects, especially when opioids are prescribed for chronic pain or addiction-related opioids. Preoperative use of opioids has been associated with worse surgical outcomes [137]. This is troubling because the use of opioids has steadily increased, and the number of readmitted patients who are tolerant to opioids is $8 \%$ [137]. Opioid-sparing multimodal analgesia protocols are a critical component of clinical practice and surgical guidelines $[138,139]$. Thus, multiple target agents such as native Pha1 $\beta$ and its recombinant version HVA calcium channel blockers and TRPA1 antagonists might be excellent candidates not only for composing a synergistic effect but also perhaps for reversing adverse effects such as tolerance [36]. Repeated morphine treatment causes tolerance, hyperalgesia, withdrawal syndrome, and constipation, but a survey by Tonello et al. [16] showed that Pha1 $\beta$ and CTK 01512-2 were able to reverse these effects. In rats, the ability of Pha1 $\beta$ to restore the analgesic effect of morphine under opioid-tolerance regimens is worth noting, suggesting some in vivo interaction of the two drugs when they are used together [36]. Administration of morphine at an ineffective dose $(3-10 \mathrm{mg} / \mathrm{kg})$ in the presence of Phal $\beta$ or CTK 01512-2 (30 pmol/site) culminates in a better analgesic effect than administering peptides or morphine alone [16]. These data showed that Pha1 $\beta$ and its recombinant version are effective in potentiating analgesia caused by a single dose of morphine as well as in reducing tolerance and the adverse effects induced by repeated administration of morphine, indicating their potential use adjuvant drugs in combination with opioids. Further studies are needed to determine the degree of interactions between the two classes of drugs involved in adverse events. In conclusion, both native Pha1 $\beta$ and CTK 01512-2 have the potential for use by parenteral route multimodal pain therapy as well as in other CNS disorders due to their varied mechanisms of action.

\section{Conclusions}

Studies with Pha1 $\beta$ and recombinant CTK 01512-2 have proven their analgesic profile in nociceptive, inflammatory, and pathological pain through HVACC and TRPA1 inhibition. Events related to molecular targets such as calcium transients, glutamate release, glial plasticity, ROS, and inflammatory mediator production have been described, supporting their antinociceptive effects and safety profiles. This review covers the 15 years of Pha1 $\beta$ research since the identification of the first target by Vieira et al. [10]. Currently, there has been an increase in the number of papers published on native and recombinant Pha1 $\beta$, stimulated by the availability of the recombinant version. Although further pharmacokinetic and preclinical (including 
toxicity profile in other species) studies are still necessary, we believe that these peptides are close to being developed as alternative clinical drugs for the severe chronic pain management and multimodal analgesia protocol application.

\section{Acknowledgments}

The authors would like to thank Antunes FTT, Borges MH, Caminski ES, Campos MM, Cordeiro MN, Daire CC, Dallegrave E, Dalmolin GD, De Pra SDT, Diniz DM, Gewehr C, Gomez RS, Lopes AMC, Marchesan S, Mazeto TK, Nicoletti NF, Prado MAM, Prado VF, Rosa F, Silva Junior CA, Silva RBM, Rossato MF, Tonello R, Trevisan G for their extensive work and contributions in the development and in understanding the mechanisms of action of Pha1 $\beta$ and recombinant CTK 01512-2. We would like to thank Editage (www.editage.com) for English language editing.

\section{Availability of data and materials}

All data included in this study are publicly available in the literature.

\section{Funding}

The presente study was supported by Instituto do Milênio MCT/ CNPq/420109/05, PADCT, Pronex CNPq, Capes Toxinologia AUXPE 1444/2011, Capes DECIT Pós Doc SUS 2865/2010, Fapemig Rede Mineira de Toxinas com Ação Terapeutica, Fapemig CBB-APQ-00855-17.

\section{Competing interests}

The authors declare that they have no competing interests.

\section{Authors' contributions}

All the authors have contributed significantly to the execution, analyses, and writing of the study. All authors read and approved the final manuscript.

\section{Ethics approval}

Not applicable.

\section{Consent for publication}

Not applicable.

\section{References}

1. Henschke N, Kamper SJ, Maher CG. The epidemiology and economic consequences of pain. Mayo Clin Proc. 2015 Jan;90(1):139-47.

2. Huang A, Azam A, Segal S, Pivovarov K, Katznelson G, Ladak SS, Mu A, Weinrib A, Katz J, Clarke H. Chronic postsurgical pain and persistent opioid use following surgery: the need for a transitional pain service. Pain Manag. 2016 Oct;6(5):435-43.

3. Tibbs GR, Posson DJ, Goldstein PA. Voltage-gated ion channels in the PNS: novel therapies for neuropathic pain? Trends Pharmacol Sci. 2016 Jul;37(7):522-42.

4. Gierthmühlen J, Baron R. Neuropathic pain. Semin Neurol. 2016 Oct;36(5):462-8.
5. Atanassoff PG, Hartmannsgruber MW, Thrasher J, Wermeling D, Longton W, Gaeta R, Singh T, Mayo M, McGuire D, Luther RR. Ziconotide, a new $\mathrm{N}$-type calcium channel blocker, administered intrathecally for acute postoperative pain. Reg Anesth Pain Med. 2000 May-Jun;25(3):274-8.

6. Lynch SS, Cheng CM, Yee JL. Intrathecal ziconotide for refractory chronic pain. Ann Pharmacother. 2006 Jul-Aug;40(7-8):1293-300.

7. Wallace MS, Kosek PS, Staats P, Fisher R, Schultz DM, Leong M. Phase II, open-label, multicenter study of combined intrathecal morphine and ziconotide: addition of ziconotide in patients receiving intrathecal morphine for severe chronic pain. Pain Med. 2008 Apr;9(3):271-81.

8. Ver Donck A, Collins R, Rauck RL, Nitescu P. An open-label, multicenter study of the safety and efficacy of intrathecal ziconotide for severe chronic pain when delivered via an external pump. Neuromodulation. 2008 Apr;11(2):103-11.

9. Thompson JC, Dunbar E, Laye RR. Treatment challenges and complications with ziconotide monotherapy in established pump patients. Pain Physician. 2006 Apr;9(2):147-52.

10. Vieira LB, Kushmerick C, Hildebrand ME, Garcia E, Stea A, Cordeiro MN, Richardson M, Gomez MV, Snutch TP. Inhibition of high voltage-activated calcium channels by spider toxin PnTx3-6. J Pharmacol Exp Ther. 2005 Sep;314(3):1370-7.

11. Woolf CJ. What is this thing called pain? J Clin Invest. 2010 Nov;120(11):3742-4.

12. Tonello R, Fusi C, Materazzi S, Marone IM, de Logu F, Benemei S, Gonçalves MC, Coppi E, Castro-Junior CJ, Gomez MV, Geppetti P, Ferreira J, Nassini R. The peptide Pha1 $\beta$, from spider venom, acts as a TRPA1 channel antagonist with antinociceptive effects in mice. Br J Pharmacol. 2017 Jan;174(1):57-69.

13. Rigo FK, Trevisan G, De Prá SDT, Cordeiro MN, Borges MH, Silva JF, Santa Cecilia FV, de Souza AH, de Oliveira Adamante G, Milioli AM, de Castro Junior CJ, Ferreira J, Gomez MV. The spider toxin Pha1 $\beta$ recombinant possesses strong analgesic activity. Toxicon. 2017 Jul;133:145-52.

14. Mogil JS. Animal models of pain: progress and challenges. Nat Rev Neurosci. 2009 Apr;10(4):283-94.

15. Souza AH, Ferreira J, Cordeiro MN, Vieira LB, De Castro CJ, Trevisan G, Reis H, Souza IA, Richardson M, Prado MAM, Prado VF, Gomez MV. Analgesic effect in rodents of native and recombinant $\mathrm{Ph}$ alpha 1 beta toxin, a high-voltage-activated calcium channel blocker isolated from armed spider venom. Pain. 2008 Nov 15;140(1):115-26.

16. Tonello R, Rigo F, Gewehr C, Trevisan G, Pereira EMR, Gomez MV, Ferreira J. Action of Pha1 $\beta$, a peptide from the venom of the spider Phoneutria nigriventer, on the analgesic and adverse effects caused by morphine in mice. J Pain. 2014 Jun;15(6):619-31.

17. Hunskaar S, Hole K. The formalin test in mice: dissociation between inflammatory and non-inflammatory pain. Pain. 1987 Jul;30(1):103-14.

18. McNamara CR, Mandel-Brehm J, Bautista DM, Siemens J, Deranian KL, Zhao M, Hayward NJ, Chong JA, Julius D, Moran MM, Fanger CM. TRPA1 mediates formalin-induced pain. Proc Natl Acad Sci U S A. 2007 Aug 14;104(33):13525-30.

19. Gregory NS, Harris AL, Robinson CR, Dougherty PM, Fuchs PN, Sluka KA. An overview of animal models of pain: disease models and outcome measures. J Pain. 2013 Nov;14(11):1255-69.

20. Ji RR, Woolf CJ. Neuronal plasticity and signal transduction in nociceptive neurons: implications for the initiation and maintenance of pathological pain. Neurobiol Dis. 2001 Feb;8(1):1-10.

21. Tjølsen A, Berge OG, Hunskaar S, Rosland JH, Hole K. The formalin test: an evaluation of the method. Pain. 1992 Oct;51(1):5-17.

22. Diniz DM, de Souza AH, Pereira EMR, da Silva JF, Rigo FK, Romano-Silva MA, Binda N, Castro Jr CJ, Cordeiro MN, Ferreira J, Gomez MV. Effects of the calcium channel blockers Pha1 $\beta$ and $\omega$-conotoxin MVIIA on capsaicin and acetic acid-induced visceral nociception in mice. Pharmacol Biochem Behav. 2014 Nov;126:97-102.

23. Silva RBM, Sperotto NDM, Andrade EL, Pereira TCB, Leite CE, de Souza AH, Bogo MR, Morrone FB, Gomez MV, Campos MM. Spinal blockage of P/Q- or $\mathrm{N}$-type voltage-gated calcium channels modulates functional and symptomatic changes related to haemorrhagic cystitis in mice. $\mathrm{Br} J$ Pharmacol. 2015 Feb;172(3):924-39.

24. Cervero F, Laird JM. Visceral pain. Lancet. 1999 Jun 19;353(9170):2145-8. 
25. Robinson DR, Gebhart GF. Inside information: the unique features of visceral sensation. Mol Interv. 2008 Oct;8(5):242-53.

26. Grundy L, Erickson A, Brierley SM. Visceral pain. Annu Rev Physiol. 2019 Feb 10;81:261-84.

27. Chan CLH, Facer P, Davis JB, Smith GD, Egerton J, Bountra C, Williams NS, Anand P. Sensory fibres expressing capsaicin receptor TRPV1 in patients with rectal hypersensitivity and faecal urgency. Lancet. 2003 Feb 1;361(9355):385-91.

28. Akbar A, Yiangou Y, Facer P, Brydon WG, Walters JRF, Anand P, Ghosh $\mathrm{S}$. Expression of the TRPV1 receptor differs in quiescent inflammatory bowel disease with or without abdominal pain. Gut. 2010 Jun;59(6):767-74.

29. Gebhart GF, Bielefeldt K. Physiology of visceral pain. Compr Physiol. 2016 Sep;6(4):1609-33.

30. Matthews PJ, Aziz Q, Facer P, Davis JB, Thompson DG, Anand P. Increased capsaicin receptor TRPV1 nerve fibres in the inflamed human oesophagus. Eur J Gastroenterol Hepatol. 2004 Sep;16(9):897-902.

31. Dang K, Bielefeldt K, Gebhart GF. Gastric ulcers reduce A-type potassium currents in rat gastric sensory ganglion neurons. Am J Physiol Gastrointest Liver Physiol. 2004 Apr;286(4):G573-9.

32. Brennan TJ, Vandermeulen EP, Gebhart GF. Characterization of a rat model of incisional pain. Pain. 1996 Mar;64(3):493-502.

33. Brennan TJ, Zahn PK, Pogatzki-Zahn EM. Mechanisms of incisional pain. Anesthesiol Clin North America. 2005 Mar;23(1):1-20.

34. Pogatzki-Zahn E, Segelcke D, Zahn P. Mechanisms of acute and chronic pain after surgery: update from findings in experimental animal models. Curr Opin Anaesthesiol. 2018 Oct;31(5):575-85.

35. de Souza AH, Lima MC, Drewes CC, da Silva JF, Torres KCL, Pereira EMR, de Castro Junior CJ, Vieira LB, Cordeiro MN, Richardson M, Gomez RS, Romano-Silva MA, Ferreira J, Gomez MV. Antiallodynic effect and side effects of Pha1 $\beta$, a neurotoxin from the spider Phoneutria nigriventer: comparison with $\omega$-conotoxin MVIIA and morphine. Toxicon. 2011 Dec 1;58(8):626-33.

36. Rigo FK, Trevisan G, Rosa F, Dalmolin GD, Otuki MF, Cueto AP, de Castro Junior CJ, Romano-Silva MA, Cordeiro MN, Richardson M, Ferreira J, Gomez MV. Spider peptide Pha1 $\beta$ induces analgesic effect in a model of cancer pain. Cancer Sci. 2013 Sep;104(9):1226-30.

37. Rigo FK, Dalmolin GD, Trevisan G, Tonello R, Silva MA, Rossato MF, Klafke JZ, Cordeiro MN, Castro Junior CJ, Montijo D, Gomez MV, Ferreira J. Effect of $\omega$-conotoxin MVIIA and Pha1 $\beta$ on paclitaxel-induced acute and chronic pain. Pharmacol Biochem Behav. 2013 Dec;114-115:16-22.

38. Plante GE, Vanltallie TB. Opioids for cancer pain: the challenge of optimizing treatment. Metabolism. 2010 Oct;59(Suppl 1):S47-52.

39. Negin BP, Riedel E, Oliveria SA, Berwick M, Coit DG, Brady MS. Symptoms and signs of primary melanoma: important indicators of Breslow depth. Cancer. 2003 Jul 15;98(2):344-8.

40. Wang $Y X$, Gao D, Pettus M, Phillips C, Bowersox SS. Interactions of intrathecally administered ziconotide, a selective blocker of neuronal $\mathrm{N}$-type voltage-sensitive calcium channels, with morphine on nociception in rats. Pain. 2000 Feb;84(2-3):271-81.

41. Yaksh TL. Calcium channels as therapeutic targets in neuropathic pain. J Pain. 2006 Jan;7(1 Suppl 1):S13-30.

42. Lee SK, Wolfe SW. Peripheral nerve injury and repair. J Am Acad Orthop Surg. 2000 Jul-Aug;8(4):243-52.

43. Zimmermann M. Pathobiology of neuropathic pain. Eur J Pharmacol. 2001 Oct 19;429(1-3):23-37.

44. Üçeyler N, Sommer C. Wallerian degeneration and neuropathic pain. Drug Discov Today Dis Mech. 2006;3(3):351-6.

45. Dubový P. Wallerian degeneration and peripheral nerve conditions for both axonal regeneration and neuropathic pain induction. Ann Anat. 2011 Jul;193(4):267-75.

46. de Souza AH, Castro Jr CJ, Rigo FK, de Oliveira SM, Gomez RS, Diniz DM, Borges MH, Cordeiro MN, Silva MAR, Ferreira J, Gomez MV. An evaluation of the antinociceptive effects of Pha1 $\beta$, a neurotoxin from the spider Phoneutria nigriventer, and $\omega$-conotoxin MVIIA, a cone snail Conus magus toxin, in rat model of inflammatory and neuropathic pain. Cell Mol Neurobiol. 2013 Jan;33(1):59-67.
47. Rosa F, Trevisan G, Rigo FK, Tonello R, Andrade EL, Cordeiro M do N, et al.Pha1 $\beta$, a peptide from the venom of the spider Phoneutria nigriventer shows antinociceptive effects after continuous infusion in a neuropathic pain model in rats. Anesth Analg. 2014 Jul;119(1):196-202.

48. Loprinzi CL, Maddocks-Christianson K, Wolf SL, Rao RD, Dyck PJB, Mantyh $P$, Dyck PJ. The paclitaxel acute pain syndrome: sensitization of nociceptors as the putative mechanism. Cancer J. 2007 Nov-Dec;13(6):399-403.

49. Flatters SJL, Bennett GJ. Ethosuximide reverses paclitaxel- and vincristineinduced painful peripheral neuropathy. Pain. 2004 May;109(1-2):150-61.

50. Rafael Nieto F, Entrena JM, Cendán CM, Del Pozo E, Vela JM, Baeyens JM. Tetrodotoxin inhibits the development and expression of neuropathic pain induced by paclitaxel in mice. Pain. 2008 Jul 31;137(3):520-31.

51. André N, Carré M, Brasseur G, Pourroy B, Kovacic H, Briand C, Braguer D. Paclitaxel targets mitochondria upstream of caspase activation in intact human neuroblastoma cells. FEBS Lett. 2002 Dec;532(1-2):256-60.

52. Zheng $\mathrm{H}, \mathrm{Xiao} \mathrm{WH}$, Bennett $\mathrm{GJ}$. Functional deficits in peripheral nerve mitochondria in rats with paclitaxel- and oxaliplatin-evoked painful peripheral neuropathy. Exp Neurol. 2011 Dec;232(2):154-61.

53. Canta A, Pozzi E, Carozzi VA. Mitochondrial dysfunction in chemotherapyinduced peripheral neuropathy (CIPN). Toxics. 2015 Jun 5;3(2):198-223.

54. Cirrincione AM, Pellegrini AD, Dominy JR, Benjamin ME, Utkina-Sosunova I, Lotti F, Jergova S, Sagen J, Rieger S. Paclitaxel-induced peripheral neuropathy is caused by epidermal ROS and mitochondrial damage through conserved MMP-13 activation. Sci Rep. 2020 Mar 4;10(1):3970.

55. Chen Y, Chen SR, Chen H, Zhang J, Pan HL. Increased a28-1-NMDA receptor coupling potentiates glutamatergic input to spinal dorsal horn neurons in chemotherapy-induced neuropathic pain. J Neurochem. 2019 Jan;148(2):252-74.

56. Shan Z, Cai S, Yu J, Zhang Z, Vallecillo TGM, Serafini MJ, Thomas AM, Pham NYN, Bellampalli SS, Moutal A, Zhou Y, Xu GB, Xu YM, Luo S, Patek M, Streicher JM, Gunatilaka AAL, Khanna R. Reversal of peripheral neuropathic pain by the small-molecule natural product physalin $\mathrm{F}$ via block of CaV2.3 (R-Type) and CaV2.2 (N-Type) voltage-gated calcium channels. ACS Chem Neurosci. 2019 Jun 19;10(6):2939-55.

57. Brandolini L, d'Angelo M, Antonosante A, Allegretti M, Cimini A. Chemokine signaling in chemotherapy-induced neuropathic pain. Int J Mol Sci. 2019 Jun 14;20(12):2904.

58. Zajączkowska R, Kocot-Kępska M, Leppert W, Wrzosek A, Mika J, Wordliczek J. Mechanisms of chemotherapy-induced peripheral neuropathy. Int J Mol Sci. 2019 Mar 22;20(6):1451.

59. Siau C, Xiao W, Bennett GJ. Paclitaxel- and vincristine-evoked painful peripheral neuropathies: loss of epidermal innervation and activation of Langerhans cells. Exp Neurol. 2006 Oct;201(2):507-14.

60. Kawakami K, Chiba T, Katagiri N, Saduka M, Abe K, Utsunomiya I, Hama T, Taguchi K. Paclitaxel increases high voltage-dependent calcium channel current in dorsal root ganglion neurons of the rat. J Pharmacol Sci. 2012;120(3):187-95.

61. Starobova H, Vetter I. Pathophysiology of chemotherapy-induced peripheral neuropathy. Front Mol Neurosci. 2017 May;10:174.

62. Chen Y, Yang C, Wang ZJ. Proteinase-activated receptor 2 sensitizes transient receptor potential vanilloid 1 , transient receptor potential vanilloid 4, and transient receptor potential ankyrin 1 in paclitaxel-induced neuropathic pain. Neuroscience. 2011 Oct 13;193:440-51.

63. Materazzi S, Fusi C, Benemei S, Pedretti P, Patacchini R, Nilius B, Prenen J, Creminon C, Geppetti P, Nassini R. TRPA1 and TRPV4 mediate paclitaxel-induced peripheral neuropathy in mice via a glutathione-sensitive mechanism. Pflugers Arch. 2012 Apr;463(4):561-9.

64. Pop-Busui R, Boulton AJM, Feldman EL, Bril V, Freeman R, Malik RA, Sosenko JM, Ziegler D. Diabetic neuropathy: a position statement by the American Diabetes Association. Diabetes Care. 2017 Jan;40(1):136-54.

65. Feldman EL, Nave KA, Jensen TS, Bennett DLH. New horizons in diabetic neuropathy: mechanisms, bioenergetics, and pain. Neuron. 2017 Mar;93(6):1296-313.

66. Albers JW, Pop-Busui R. Diabetic neuropathy: mechanisms, emerging treatments, and subtypes. Curr Neurol Neurosci Rep. 2014 Aug;14(8):473. 
67. Hicks CW, Selvin E. Epidemiology of peripheral neuropathy and lower extremity disease in diabetes. Curr Diab Rep. 2019 Aug 27;19(10):86.

68. da Silva Junior CA, de Castro Junior CJ, Pereira EMR, Binda NS, da Silva JF, do Nascimento Cordeiro M, Diniz DM, Cecilia FS, Ferreira J, Gomez MV. The inhibitory effect of Pha1 $\beta$ toxin on diabetic neuropathic pain involves the CXCR4 chemokine receptor. Pharmacol Rep. 2020 Feb;72(1):47-54.

69. Penn RD, Paice JA. Adverse effects associated with the intrathecal administration of ziconotide. Pain. 2000 Mar;85(1-2):291-6.

70. Staats PS, Yearwood T, Charapata SG, Presley RW, Wallace MS, ByasSmith M, Fisher R, Bryce DA, Mangieri EA, Luther RR, Mayo M, McGuire $D$, Ellis $D$. Intrathecal ziconotide in the treatment of refractory pain in patients with cancer or AIDS: a randomized controlled trial. JAMA. 2004 Jan 7;291(1):63-70.

71. Schmidtko A., Lötsch J, Freynhagen R, Geisslinger G. Ziconotide for treatment of severe chronic pain. Lancet. 2010 May 1;375(9725):1569-77

72. Miljanich GP, Ramachandran J. Antagonists of neuronal calcium channels: structure, function, and therapeutic implications. Annu Rev Pharmacol Toxicol. 1995;35:707-34.

73. Skov MJ, Beck JC, de Kater AW, Shopp GM. Nonclinical safety of ziconotide: an intrathecal analgesic of a new pharmaceutical class. Int J Toxicol. 2007 Sep-Oct;26(5):411-21.

74. Wright CE, Robertson AD, Whorlow SL, Angus JA. Cardiovascular and autonomic effects of $\omega$-conotoxins MVIIA and CVID in conscious rabbits and isolated tissue assays. Br J Pharmacol. 2000 Dec;131(7):1325-36.

75. Bowersox SS, Gadbois T, Singh T, Pettus M, Wang YX, Luther RR. Selective $\mathrm{N}$-type neuronal voltage-sensitive calcium channel blocker, SNX111, produces spinal antinociception in rat models of acute, persistent and neuropathic pain. J Pharmacol Exp Ther. 1996 Dec;279(3):1243-9.

76. Staats PS, Hekmat H, Staats AW. The psychological behaviorism theory of pain and the placebo: its principles and results of research application. Adv Psychosom Med. 2004; 25:28-40.

77. Wallace MS, Charapata SG, Fisher R, Byas-Smith M, Staats PS, Mayo M, McGuire D, Ellis D, Ziconotide Nonmalignant Pain Study 96-002 Group. Intrathecal ziconotide in the treatment of chronic nonmalignant pain: a randomized, double-blind, placebo-controlled clinical trial. Neuromodulation. 2006 Apr;9(2):75-86. doi: 10.1111/j.15251403.2006.00055.x. PubMed PMID: 22151630.

78. Staats PS, Yearwood T, Charapata SG, Presley RW, Wallace MS, ByasSmith M, Fisher R, Bryce DA, Mangieri EA, Luther RR, Mayo M, McGuire $D$, Ellis $D$. Intrathecal ziconitide in the treatment of refractory pain in patients with cancer or AIDS: a randomized controlled trial. JAMA. 2004 Jan 7;291(1):63-70.

79. Malmberg AB, Yaksh TL. Voltage-sensitive calcium channels in spinal nociceptive processing: blockade of $\mathrm{N}$ - and P-type channels inhibits formalin-induced nociception. J Neurosci. 1994 Aug;14(8):4882-90.

80. Snutch TP. Targeting chronic and neuropathic pain: the N-type calcium channel comes of age. NeuroRx. 2005 Oct;2(4):662-70.

81. Dallegrave E, Taschetto E, Leal MB, Antunes FTT, Gomez MV, de Souza $\mathrm{AH}$. Acute toxicity of the recombinant and native pha1toxin: new analgesic from Phoneutria nigriventer spider venom. Toxins (Basel). 2018 Dec 12;10(12):531.

82. de Souza AH, da Rosa LG, Uliano MR, da Silva Prado L, Ferraz AG, Conter LU, Grivicich I, Dallegrave E, Gomez MV, Picada JN. Evaluation of DNA damage in spinal cord and mutagenic effect of a Pha1 $\beta$ recombinant toxin with analgesic properties from the Phoneutria nigriventer spider. Basic Clin Pharmacol Toxicol. 2019 May;124(5):615-20.

83. De Logu F, Geppetti P. Ion channel pharmacology for pain modulation. Handb Exp Pharmacol. 2019;260:161-86.

84. Zamponi GW, Striessnig J, Koschak A, Dolphin AC. The physiology, pathology, and pharmacology of voltage-gated calcium channels and their future therapeutic potential. Pharmacol Rev. 2015 Oct;67(4):821-70.

85. Zamponi GW, Lewis RJ, Todorovic SM, Arneric SP, Snutch TP. Role of voltage-gated calcium channels in ascending pain pathways. Brain Res Rev. 2009 Apr;60(1):84-9.

86. Schroeder $\mathrm{Cl}$, Doering CJ, Zamponi GW, Lewis RJ. N-type calcium channel blockers: novel therapeutics for the treatment of pain. Med Chem. 2006 Sep;2(5):535-43.
87. Vieira LB, Kushmerick C, Reis HJ, Diniz CR, Cordeiro MN, Prado MAM, Kalapothakis E, Romano-Silva MA, Gomez MV. PnTx3-6 a spider neurotoxin inhibits $\mathrm{K}+$-evoked increase in $\left[\mathrm{Ca}^{2+}\right]_{i}$ and $\mathrm{Ca}^{2+}$ - dependent glutamate release in synaptosomes. Neurochem Int. 2003 Mar;42(4):277-82.

88. Bean, BP. Nitrendipine block of cardiac calcium channels: high-affinity binding to the inactivated state. Proc Natl Acad Sci U S A. 1984 Oct;81(20):6388-92.

89. Feng ZP, Doering CJ, Winkfein RJ, Beedle AM, Spafford JD, Zamponi GW. Determinants of inhibition of transiently expressed voltage-gated calcium channels by omega-conotoxins GVIA and MVIIA. J Biol Chem. 2003 May 30;278(22):20171-8.

90. Kádková A, Synytsya V, Krusek J, Zímová L, Vlachová V. Molecular basis of TRPA1 regulation in nociceptive neurons. A review. Physiol Res. 2017 Jul 18;66(3):425-39.

91. Meents JE, Ciotu Cl, Fischer MJM. TRPA1: a molecular view. J Neurophysiol. 2019 Feb 1;121(2):427-43.

92. Chen J, Luan Y, Yu R, Zhang Z, Zhang J, Wang W. Transient receptor potential (TRP) channels, promising potential diagnostic and therapeutic tools for cancer. Biosci Trends. 2014 Feb;8(1):1-10.

93. Maatuf $\mathrm{Y}$, Geron $M$, Priel $A$. The role of toxins in the pursuit for novel analgesics. Toxins (Basel). 2019 Feb 23;11(2):131.

94. Castro-Junior CJ, Milano J, Souza AH, Silva JF, Rigo FK, Dalmolin G, Cordeiro MN, Richardson M, Barros AGA, Gomez RS, Silva MAR, Kushmerick C, Ferreira J, Gomez MV. Pha1 $\beta$ toxin prevents capsaicininduced nociceptive behavior and mechanical hypersensitivity without acting on TRPV1 channels. Neuropharmacology. 2013 Aug;71:237-46.

95. Gruner W, Silva LR. Omega-conotoxin sensitivity and presynaptic inhibition of glutamatergic sensory neurotransmission in vitro. J Neurosci. 1994 May:14(5):2800-8.

96. Gadotti VM, Martins DF, Pinto HF, Oliveira G, Kaster MP, Quintão NLM, Santos ARS. Diacerein decreases visceral pain through inhibition of glutamatergic neurotransmission and cytokine signaling in mice. Pharmacol Biochem Behav. 2012 Oct;102(4):549-54.

97. Xu B, Descalzi G, Ye HR, Zhuo M, Wang YW. Translational investigation and treatment of neuropathic pain. Mol Pain. 2012 Mar 9;8:15.

98. da Silva JF, Castro-Junior CJ, Oliveira SM, Dalmolin GD, Silva CR, Vieira LB, Diniz DM, Cordeiro MN, Ferreira J, Souza AH, Gomez MV. Characterization of the antinociceptive effect of $\mathrm{PhT} \times 3-4$, a toxin from Phoneutria nigriventer, in models of thermal, chemical and incisional pain in mice. Toxicon. 2015 Dec 15;108:53-61.

99. Kallenborn-Gerhardt W, Schröder K, Del Turco D, Lu R, Kynast K, Kosowski J, Niederberger E, Shah AM, Brandes RP, Geisslinger G, Schmidtko A. NADPH oxidase-4 maintains neuropathic pain after peripheral nerve injury. J Neurosci. 2012 Jul 25;32(30):10136-45.

100. Ogawa N, Kurokawa T, Mori Y. Sensing of redox status by TRP channels. Cell Calcium. 2016 Aug;60(2):115-22.

101. Görlach A, Bertram K, Hudecova S, Krizanova O. Calcium and ROS: a mutual interplay. Redox Biol. 2015 Dec;6:260-71.

102. Gordeeva AV, Zvyagilskaya RA, Labas YA. Cross-talk between reactive oxygen species and calcium in living cells. Biochemistry (Mosc). 2003 Oct;68(10):1077-80.

103. Carrasco C, Naziroğlu M, Rodríguez AB, Pariente JA. Neuropathic pain: delving into the oxidative origin and the possible implication of transient receptor potential channels. Front Physiol. 2018 Feb 14;9:95.

104. Andersson DA, Filipović MR, Gentry C, Eberhardt M, Vastani N, Leffler A, Reeh P, Bevan S. Streptozotocin stimulates the ion channel TRPA1 directly:involvement of peroxynitrite. J Biol Chem. 2015 Jun 12;290(24):15185-96.

105. Jardín I, López JJ, Diez R, Sánchez-Collado J, Cantonero C, Albarrán L, Woodard GE, Redondo PC, Salido GM, Smani T, Rosado JA. TRPs in pain sensation. Front Physiol. 2017 Jun 9;8:392.

106. Park J, Zheng L, Acosta G, Vega-Alvarez S, Chen Z, Muratori B, Cao P, Shi R. Acrolein contributes to TRPA1 up-regulation in peripheral and central sensory hypersensitivity following spinal cord injury. J Neurochem. 2015 Dec;135(5):987-97.

107. Klafke JZ, da Silva MA, Rossato MF, de Prá SDT, Rigo FK, Walker CIB, Bochi GV, Moresco RN, Ferreira J, Trevisan G. Acute and chronic nociceptive phases observed in a rat hind paw ischemia/reperfusion model depend on different mechanisms. Pflugers Arch. 2016 Feb;468(2):229-41. 
108. Nazıroğlu M, Braidy N. Thermo-sensitive TRP channels: novel targets for treating chemotherapy-induced peripheral pain. Front Physiol. 2017 Dec 13;8:1040.

109. Ates O, Cayli SR, Gurses I, Turkoz Y, Tarim O, Cakir CO, Kocak A. Comparative neuroprotective effect of sodium channel blockers after experimental spinal cord injury. J Clin Neurosci. 2007 Jul;14(7):658-65.

110. Sajic M. Mitochondrial dynamics in peripheral neuropathies. Antioxid Redox Signal. 2014 Aug 1;21(4):601-20.

111. Watkins LR, Milligan ED, Maier SF. Glial activation: a driving force for pathological pain. Trends Neurosci. 2001 Aug;24(8):450-5.

112. Milligan ED, Watkins LR. Pathological and protective roles of glia in chronic pain. Nat Rev Neurosci. 2009 Jan;10(1):23-36.

113. Sorge RE, Mapplebeck JCS, Rosen S, Beggs S, Taves S, Alexander JK, Martin LJ, Austin JS, Sotocinal SG, Chen D, Yang M, Shi XQ, Huang H, Pillon NJ, Bilan PJ, Tu Y, Klip A, Ji RR, Zhang J, Salter MW, Mogil JS. Different immune cells mediate mechanical pain hypersensitivity in male and female mice. Nat Neurosci. 2015 Aug;18(8):1081-3.

114. Talbot S, Foster SL, Woolf CJ. Neuroimmunity: physiology and pathology. Annu Rev Immunol. 2016 May 20;34:421-47.

115. Tenza-Ferrer H, Magno LAV, Romano-Silva MA, da Silva JF, Gomez MV. Pha1 $\beta$ spider toxin reverses glial structural plasticity upon peripheral inflammation. Front Cell Neurosci. 2019 Jul 10;13:306.

116. Xu F, Li Y, Li S, Ma Y, Zhao N, Liu Y, Qian N, Zhao H, Li Y. Complete Freund's adjuvant-induced acute inflammatory pain could be attenuated by triptolide via inhibiting spinal glia activation in rats. J Surg Res. 2014 May 1;188(1):174-82.

117. Fu ES, Zhang YP, Sagen J, Candiotti KA, Morton PD, Liebl DJ, Bethea JR, Brambilla R. Transgenic inhibition of glial NF-kappa B reduces pain behavior and inflammation after peripheral nerve injury. Pain. 2010 Mar;148(3):509-18.

118. Ikeda H, Kiritoshi T, Murase K. Contribution of microglia and astrocytes to the central sensitization, inflammatory and neuropathic pain in the juvenile rat. Mol Pain. 2012 Jun 15;8:43.

119. Raghavendra V, Tanga FY, DeLeo JA. Complete Freunds adjuvant-induced peripheral inflammation evokes glial activation and proinflammatory cytokine expression in the CNS. Eur J Neurosci. 2004 Jul;20(2):467-73.

120. Hains BC, Waxman SG. Activated microglia contribute to the maintenance of chronic pain after spinal cord injury. J Neurosci. 2006 Apr 19;26(16):4308-17.

121. Romero-Sandoval A, Chai N, Nutile-McMenemy N, Deleo JA. A comparison of spinal lba1 and GFAP expression in rodent models of acute and chronic pain. Brain Res. 2008 Jul 11;1219:116-26.

122. Sontheimer H. Voltage-dependent ion channels in glial cells. Glia. 1994 Jun;11(2):156-72.

123. Kettenmann H, Ransom BR. Neuroglia. 3rd ed. New York: Oxford University Press; 2013.

124. Eichhoff G, Brawek B, Garaschuk O. Microglial calcium signal acts as a rapid sensor of single neuron damage in vivo. Biochim Biophys Acta. 2011 May;1813(5):1014-24.

125. Stebbing MJ, Cottee JM, Rana I. The role of ion channels in microglial activation and proliferation-a complex interplay between ligand-gated ion channels, $\mathrm{K}(+)$ channels, and intracellular $\mathrm{Ca}(2$.). Front Immunol. 2015 Oct 22;6:497.
126. Wormwood KL, Ngounou Wetie AG, Gomez MV, Ju Y, Kowalski P, Mihasan M, Darie CC. Structural characterization and disulfide assignment of spider peptide Pha1 $\beta$ by mass spectrometry. J Am Soc Mass Spectrom. 2018 May;29(5):827-41.

127. Antunes FTT, Angelo SG, Dallegrave E, Picada JN, Marroni NP, Schemitt E, Ferraz AG, Gomez MV, de Souza AH. Recombinant peptide derived from the venom the Phoneutria nigriventer spider relieves nociception by nerve deafferentation. Neuropeptides. 2020 Feb;79:101980.

128. De Rossi SS. Orofacial pain: a primer. Dent Clin North Am. 2013 Jul;57(3):383-92.

129. Shaefer JR, Khawaja SN, Bavia PF. Sex, gender, and orofacial pain. Dent Clin North Am. 2018 Oct;62(4):665-82.

130. Caminski ES, de Freitas LM, Dallegrave E, da Silva Junior CA, Gomez MV, Pereira EMR, Antunes FTT, de Souza AH. Analgesic effects of the CTK 01512-2 toxin in different models of orofacial pain in rats. Pharmacol Rep. 2020 Jun;72(3):600-11.

131. Nicoletti NF, Erig TC, Zanin RF, Roxo MR, Ferreira NP, Gomez MV, Morrone FB, Campos MM. Pre-clinical evaluation of voltage-gated calcium channel blockers derived from the spider $P$. nigriventer in glioma progression. Toxicon. 2017 Apr;129:58-67.

132. Silva RBM, Greggio S, Venturin GT, da Costa JC, Gomez MV, Campos MM. Beneficial effects of the calcium channel blocker CTK 01512-2 in a mouse model of multiple sclerosis. Mol Neurobiol. 2018 Dec;55(12):9307-27.

133. Carvalho VRP, da Silva JF, Buzelin MA, da Silva Júnior CA, Dos Santos DC, Diniz DM, Binda NS, Borges MH, Senna Guimarães AL, Rita Pereira EM, Gomez MV. Calcium channels blockers toxins attenuate abdominal hyperalgesia and inflammatory response associated with the ceruleininduced acute pancreatitis in rats. Eur J Pharmacol. 2021 Jan 15;891:173672. doi: 10.1016/j.ejphar.2020.173672.

134. Rigo FK, Rossato MF, Borges V, da Silva JF, Pereira EMR, de Ávila RAM, Trevisan G, Dos Santos DC, Diniz DM, Silva MAR, de Castro CJ, Cunha TM, Ferreira J, Gomez MV. Analgesic and side effects of intravenous recombinant Pha1 $\beta$. J Venom Anim Toxins incl Trop Dis. 2020 Apr 17;26:e20190070.

135. De Prá SDT, Antoniazzi CTD, Ferro PR, Kudsi SQ, Camponogara C, Fialho MFP, Rigo FK, Gomez MV, Bochi GV, Moresco RN, Oliveira SM, Trevisan G. Nociceptive mechanisms involved in the acute and chronic phases of a complex regional pain syndrome type 1 model in mice. Eur J Pharmacol. 2019 Sep 15;859:172555.

136. Cooney MF. Management of postoperative pain in opioid-tolerant patients. J perianesthesia Nurs. 2015 Oct;30(5):436-43.

137. Cozowicz C, Olson A, Poeran J, Mörwald EE, Zubizarreta N, Girardi FP, Hughes AP, Mazumdar M, Memtsoudis SG. Opioid prescription levels and postoperative outcomes in orthopedic surgery. Pain. 2017 Dec;158(12):2422-30.

138. Gulur P, Williams L, Chaudhary S, Koury K, Jaff M. Opioid tolerance--a predictor of increased length of stay and higher readmission rates. Pain Physician. 2014 Jul-Aug;17(4):E503-7.

139. Truong A, Mujukian A, Fleshner P, Zaghiyan K. No pain, more gain: reduced postoperative opioid consumption with a standardized opioid-sparing multimodal analgesia protocol in opioid-tolerant patients undergoing colorectal surgery. Am Surg. 2019 Oct 1;85(10):1155-8. 